Published in final edited form as:

Cochrane Database Syst Rev. ; 1: CD008213. doi:10.1002/14651858.CD008213.pub2.

\title{
Surgical interventions for primary congenital glaucoma
}

\author{
Deepta Ghate ${ }^{1}$ and Xue Wang ${ }^{2}$ \\ ${ }^{1}$ Department of Ophthalmology and Visual Sciences, University of Nebraska Medical Center, \\ Omaha, Nebraska, USA \\ 2Department of Epidemiology, Johns Hopkins Bloomberg School of Public Health, Baltimore, \\ Maryland, USA
}

\begin{abstract}
Background-Primary congenital glaucoma (PCG) manifests within the first few years of a child's life and is not associated with any other systemic or ocular abnormalities. PCG results in considerable morbidity even in developed countries. Several surgical techniques for treating this condition, and lowering the intraocular pressure (IOP) associated with it, have been described.
\end{abstract}

Objectives-To compare the effectiveness and safety of different surgical techniques for PCG.

Search methods-We searched CENTRAL (which contains the Cochrane Eyes and Vision Group Trials Register) (The Cochrane Library 2014, Issue 6), Ovid MEDLINE, Ovid MEDLINE In-Process and Other Non-Indexed Citations, Ovid MEDLINE Daily, Ovid OLDMEDLINE (January 1946 to June 2014), EMBASE (January 1980 to June 2014), (January 1982 to June 2014), PubMed (January 1946 to June 2014), the metaRegister of Controlled Trials ( $m$ RCT) (www.controlled-trials.com), ClinicalTrials.gov (www.clinicaltrials.gov), the WHO International Clinical Trials Registry Platform (ICTRP) (www.who.int/ictrp/search/en). We did not use any date or language restrictions in the electronic searches for trials. We last searched the electronic databases on 23 June 2014.

Selection criteria-We included all randomized and quasi-randomized trials in which different types of surgical interventions were compared in children under five years of age with PCG.

Data collection and analysis-We used standard methodological procedures specified by The Cochrane Collaboration.

\footnotetext{
Copyright () 2015 The Cochrane Collaboration. Published by John Wiley \& Sons, Ltd.

Contact address: Deepta Ghate, Department of Ophthalmology and Visual Sciences, University of Nebraska Medical Center, 985540 Nebraska Medical Center, Omaha, Nebraska, 68198-5540, USA. deeptaghate@gmail.com.

CONTRIBUTIONS OF AUTHORS

DG and SK (Sachin Kedar) conceived the review question.

DG and XW coordinated the review, screened search results, organized retrieval of papers, screened retrieved paper against inclusion criteria, appraised quality of papers, extracted data from papers, provided additional data about papers, obtained and screened data on unpublished studies, analyzed data, and provided a methodological perspective.

XW entered data into RevMan and DG verified the data entry.

DG and XW provided clinical, policy and consumer perspectives and provided general advice on the review.

DG and XW wrote the review.

DG and SK performed previous work that was the foundation of the current review (Ghate 2010).
}

DECLARATIONS OF INTEREST

None known. 
Main results-We included a total of six trials (four randomized and two quasi-randomized) with 102 eyes in 61 children. Two trials were conducted in the USA and one trial each in Egypt, Israel, Lebanon and Saudi Arabia. All trials included children aged younger than one year when diagnosed with PCG, and followed them for periods ranging from six months to five years.

No two trials compared the same pair of surgical interventions, so we did not perform any metaanalysis. One trial compared trabeculotomy versus goniotomy; a second trial compared combined trabeculectomy-trabeculotomy with mitomycin $\mathrm{C}$ versus trabeculectomy-trabeculotomy with mitomycin $\mathrm{C}$ and deep sclerectomy; a third trial compared combined trabeculotomytrabeculectomy versus trabeculotomy; a fourth trial compared one goniotomy versus two goniotomies; a fifth trial compared trabeculotomy versus viscocanalostomy; and the sixth trial compared surgical goniotomy versus neodymium-YAG laser goniotomy. For IOP change and surgical success (defined by IOP achieved), none of the trials reported a difference between pairs of surgical techniques. However, due to the limited sample sizes for all trials (average of 10 children per trial), the evidence as to whether a particular surgical technique is effective and which surgical technique is better still remains uncertain. Adverse events, such as choroidal detachment, shallow anterior chamber and hyphema, were reported from four trials. None of the trials reported quality of life or economic data.

These trials were neither designed nor reported well overall. Two trials were quasi-randomized trials and judged to have high risk of selection bias; four trials were at unclear or high risk for performance bias and detection bias; and we judged one trial to have high risk of attrition bias due to high proportions of losses to follow-up. Due to poor study design and reporting, the reliability and applicability of evidence remain unclear.

Authors' conclusions-No conclusions could be drawn from the trials included in this review due to paucity of data. More research is needed to determine which of the many surgeries performed for PCG are effective.

\section{PLAIN LANGUAGE SUMMARY}

\section{Surgical interventions for childhood glaucoma}

Review question-This review compared the effects of different surgeries for primary congenital glaucoma (PCG).

Background-PCG is a type of childhood glaucoma, usually beginning in the first five years of life. PCG is caused by an abnormal drainage system in the eye in the absence of other eye or health problems. Fluid naturally produced by the eye builds up causing high pressure within the eye. In children younger than five years, the high fluid pressure can cause the eye to enlarge (distend) leading to a cloudy cornea (clear front part of the eye), decreased vision, tearing, and light sensitivity. Failure to treat this condition may result in partial or total blindness.

PCG is primarily treated by surgery to reduce the pressure in the eye. Some surgeries aim to open up the drainage system of the eye either from the inside (goniotomy) or the outside (trabeculotomy, viscocanalostomy). Other surgeries involve making a new drainage pathway for the eye (trabeculectomy, deep sclerectomy, implantation of a device). Drugs, such as 
mitomycin $\mathrm{C}$, also may be used during surgeries to prevent the drainage openings from closing up.

Study characteristics-We found six trials comparing different surgeries for PCG. These trials included 102 eyes of 61 children. Two trials were conducted in the USA and one trial in each of these four countries: Egypt, Israel, Lebanon and Saudi Arabia. All trials enrolled infants younger than one year when diagnosed with PCG, and followed them from six months to five years after surgery. No two trials compared the same pair of surgical interventions. One trial compared trabeculotomy versus goniotomy; the second trial compared combined trabeculectomy-trabeculotomy with mitomycin C (CTTM) versus trabeculectomy-trabeculotomy with mitomycin $\mathrm{C}$ with deep sclerectomy (CTTM-DS); the third trial compared combined trabeculotomy-trabeculectomy versus trabeculotomy; the fourth trial compared one goniotomy versus two goniotomies; the fifth trial compared trabeculotomy versus viscocanalostomy; and the sixth trial compared goniotomy using a blade versus a laser. The evidence is current to 23 June 2014.

Key results-In our review, no two trials compared the same pair of operations. Further, there were small numbers of children included in each trial (average of 10 children per trial), thus limiting our ability to draw conclusions about the effectiveness of one surgery over another. Four trials reported adverse events, but no trial reported an important difference between pairs of operations. None of the trials reported quality of life or economic data.

Quality of the evidence-The overall quality of the evidence on our review topic was poor. All trials had some limitations in study design, reporting, or both. None of the trials enrolled enough participants to detect an evident difference between surgeries.

\section{BACKGROUND}

\section{Description of the condition}

Definition and epidemiology_Pediatric glaucomas are a group of potentially blinding conditions characterized by elevated intraocular pressure (IOP) and subsequent damage to the optic nerve. Primary congenital glaucoma (PCG) occurs before five years of age and is not associated with any other systemic or ocular abnormality apart from isolated trabeculodysgenesis (malformation of the trabecular meshwork) (Stamper 2009).

According to the World Health Organization estimates in 1994, 300,000 children had congenital glaucoma worldwide, of whom an estimated 200,000 were blind due to PCG (Thylefors 1994). The incidence of pediatric glaucoma varies dramatically with race, ethnicity, and level of consanguinity (i.e. the number of blood relatives) in the community (Papadopoulos 2007). The incidence of PCG varies from 1:10,000 to 1:20,000 live births in western countries (Francois 1980; Gencick 1982; Miller 1966; Papadopoulos 2007) to 1:1250 in Slovakian gypsies (Gencick 1982). Congenital glaucoma is responsible for between $4 \%$ to $18 \%$ of all childhood blindness (Dorairaj 2008; Franks 1989; Gilbert 1994; Haddad 2007; Sitorus 2007). 
Presentation and diagnosis-PCG represents $19 \%$ to $38 \%$ of all pediatric glaucoma in different populations in the USA and Canada (Barsoum-Homsy 1989; Fung 2013; Taylor 1999). PCG is bilateral in $70 \%$ to $80 \%$ of cases (Francois 1980; Morin 1974). Most cases present within six months of birth, with nearly $80 \%$ presenting before one year of age (Allingham 2005a; Papadopoulos 2007).

Neonatal and infantile globes are distensible which results in globe enlargement (buphthalmos) when IOP is elevated. Corneal changes are often the presenting features of PCG and result in the classical clinical triad of epiphora (excessive tearing of eyes), blepharospasm (involuntary blinking of the eyelids), and photophobia (light sensitivity). Corneal diameters that are asymmetric, or a corneal diameter greater than $13 \mathrm{~mm}$ at any age, or greater than $11.5 \mathrm{~mm}$ at birth (normal $9.5 \mathrm{~mm}$ to $10 \mathrm{~mm}$ at birth and $10 \mathrm{~mm}$ to $12 \mathrm{~mm}$ at two years) warrant further evaluation for glaucoma (Allingham 2005a; Kiskis 1985; Sampaolesi 1982; Stamper 2009). Other corneal changes include corneal edema, corneal haze, Haab's striae (breaks in Descemet's membrane), and corneal opacities. An axial length (AL) greater than $20 \mathrm{~mm}$ at birth (normal $16 \mathrm{~mm}$ to $17 \mathrm{~mm}$ ) or $22.5 \mathrm{~mm}$ at one year (normal $20.1 \mathrm{~mm}$ ) is suspicious for glaucoma (Stamper 2009). Gonioscopy in eyes with PCG shows a characteristic angle structure with an anterior iris insertion, fine iris processes, and altered translucency of the angle face, historically called the Barkan's membrane (Allingham 2005a; Barkan 1955). The iris, lens, and the other parts of the anterior segment appear normal. Optic nerve findings in PCG resemble those seen in adult glaucoma. In a child, the scleral canal is distensible, and cupping in PCG proceeds more rapidly and is occasionally reversible (Quigley 1977; Quigley 1982; Robin 1979). A cup/disc ratio greater than 0.3 also may be indicative of glaucoma (normal $0 \mathrm{~mm}$ to 0.1 from birth to two years and $0.1 \mathrm{~mm}$ to 0.2 from two to six years) (Amer 2014).

The intrinsic abnormality in PCG lies in the angle. The corneal and optic disc features are associated with the rise in IOP and are shared by other infantile glaucomas. The underlying reason for the lower aqueous outflow (block in the aqueous pathways) has yet to be elucidated. Studies have shown that the PCG eye has the clinical characteristics of an immature eye in the seventh or eighth month of gestation with a very anterior insertion of the iris (Anderson 1981). Anderson 1981 has hypothesized that excess or abnormal collagenous beams with the trabecular meshwork may prevent the normal posterior migration of the ciliary body during development that leads to the extremely anterior iris insertion.

Prognosis-The prognosis of childhood glaucoma is affected by the age of glaucoma onset, the diagnosis, associated ocular defects and the treatment. Children with PCG have a better prognosis with treatment than children who have associated systemic or ocular anomalies or secondary glaucomas (Kargi 2006), although most untreated cases of PCG progress to blindness (Allingham 2005a).

The most favorable prognosis is for children presenting between two months and one year of age, who have a 90\% chance of IOP control with surgery (deLuise 1983; Haas 1968). The worst prognosis is for children presenting at birth or after one year of age, who have a 50\% 
chance of IOP control (deLuise 1983; Haas 1968). Thus, despite treatment, the prognosis for useful vision remains grim in many children with PCG.

\section{Description of the intervention}

Surgical therapy-Surgical therapy is the accepted standard treatment for PCG, with angle surgery (goniotomy or trabeculotomy) generally used as the primary intervention (Allingham 2005b; Stamper 2009). There is considerable heterogeneity in the management of PCG even amongst experts in the field.

1. Angle surgeries: Goniotomy initially was described by Otto Barkan in 1938 (Allingham 2005b; Barkan 1938). A goniolens is used to visualize the angle structures and a needle or a knife (or rarely a laser beam) penetrates the anterior chamber and is used to incise the trabecular meshwork circumferentially for 120 degrees. If the first goniotomy fails, a second goniotomy can be performed that incises previously untouched trabecular meshwork through a second corneal incision. In trabeculotomy, an external approach is used to reach the Schlemm's canal, followed by rotation of a probe into the anterior chamber, thereby opening up 120 degrees of the angle. Trabeculotomy is not dependent on corneal clarity. A modification of the procedure uses a 6-0 polypropylene suture or a catheter advanced into the Schlemm's canal which can open up 360 degrees of the angle (Beck 1995; Mendicino 2000). Viscocanalostomy is a procedure in which Schlemm's canal is identified under a scleral flap and then dilated using a viscoelastic.

2. Filtering surgeries: Trabeculectomy is a filtering procedure for the eye, in which a fistula is created under a scleral flap into the anterior chamber allowing aqueous to drain from the anterior chamber into the subconjunctival space. Drugs such as mitomycin C (MMC) may be used to prevent scarring of the subconjunctival space in order to maintain the drainage opening. In PCG, trabeculectomy (with or without MMC) is typically reserved as a second procedure after failure of angle surgery or is used in a combined approach with trabeculotomy. Children, especially infants, have a better healing response than adults, which can lead to scarring of the fistula or the conjunctiva, resulting in worse surgical outcomes with trabeculectomy than for adults. Children with trabeculectomies are subject to the same complications as adults, with the added caveat that any procedure performed after the surgery, such as suture lysis or 5-fluorouracil injections, also must be done under general anesthesia. The rates of bleb-related endophthalmitis (intraocular inflammation) are high, ranging from $7 \%$ to $14 \%$, and highlight the need for lifelong follow-up of these children (Beck 1998; Freedman 1999; Sidoti 2000; Waheed 1997). Deep sclerectomy is a nonpenetrating surgery in which the Schlemm's canal is unroofed under a scleral flap without entering the anterior chamber. Combined trabeculectomy-trabeculotomy procedures are favored by some specialists as the first choice of surgery for children with PCG, especially children who are at a high risk for surgical failure, i.e. children who are older than one year and children with advanced or long-standing untreated disease (Elder 1994).

3. Glaucoma drainage devices: Glaucoma drainage devices (GDD) are devices that act as shunts for the aqueous to drain from the anterior chamber to a posterior drainage area around a plate sutured to the sclera. In PCG, they are usually reserved for refractory cases in which 
angle surgery or trabeculectomy either did not work or was not applicable, although several glaucoma specialists may use GDDs earlier in secondary pediatric glaucomas. Pediatric models of most GDDs are available; the surgical technique is similar to that used in adults. Complications of GDD in children are similar to those in adults and include tube complications (corneal touch, implant exposure, tube block, dislocation), motility disturbances and infection (Al-Torbaq 2002; Gutierrez-Diaz 2001; Munoz 1991).

4. Cyclodestructive procedures: As in adults, cyclodestructive procedures are those of last resort in refractory pediatric glaucomas. The ciliary body can be destroyed using cyclocryotherapy (freezing temperatures), transcleral cyclophotocoagulation (laser) or endoscopic cyclophotocoagulation (laser with endoscope). Complications are similar to those in adults and include hypotony (low IOP), phthisis (shrinkage of the eyeball), uveitis (inflammation of the middle layer of the eye), cataracts and visual loss.

Medical therapy-Medical therapy plays an important auxiliary role in the management of PCG (Allingham 2005b). Systemic side effects have to be monitored with greater care in children especially in vulnerable neonates. Beta-blockers (Boger 1983;Hoskins 1985), systemic (deLuise 1983; Portellos 1998) and topical (Portellos 1998) carbonic anhydrase inhibitors have been shown to be effective in PCG although the systemic side effects require monitoring (deLuise 1983; Olson 1979; Passo 1984; Portellos 1998). Prostaglandin analogues (Enyedi 2002) and miotics (Allingham 2005b) may not be as effective in infants with PCG as adults. Brimonidine is contraindicated in children weighing less than $40 \mathrm{lbs}$ due to its effects on the central nervous system in children (Carlsen 1999). Apraclonidine has been reported to lower the IOP in children and to have fewer central nervous system side effects compared to brimonidine (Wright 2009).

\section{How the intervention might work}

Angle surgery aims to open a route for aqueous humor to flow into the Schlemm's canal by physically removing the obstruction at the angle. The precise mechanism of IOP lowering remains obscure; theoretically, aqueous outflow should increase to reduce pressure in the anterior portion of the eye (Grehn 1995).

Filtering surgery and glaucoma shunt surgery work by creating a separate drainage pathway for the aqueous either through a fistula in the eye into a conjunctival bleb in the case of a trabeculectomy, or into an aqueous reservoir in the case of a glaucoma shunt.

Cyclodestructive procedures destroy the ciliary body and lower aqueous production.

\section{Why it is important to do this review}

Although most specialists agree that surgery, specifically angle surgery, is the procedure of first choice for PCG, there are considerable differences in management approaches and treatment algorithms. There are staunch supporters of both goniotomy and trabeculotomy, as well as other surgical techniques including trabeculectomy-trabeculotomy. Study investigators often have used different definitions of surgical success and have drawn participants from different pediatric glaucoma populations. It is unclear which surgical treatment is most effective to achieve or assure useful vision for children diagnosed with 
PCG. A systematic review comparing the success rates and complication rates of different surgical interventions is essential to answer this question.

\section{OBJECTIVES}

To compare the effectiveness and safety of different surgical techniques for PCG.

\section{METHODS}

\section{Criteria for considering studies for this review}

Types of studies-We included randomized controlled trials (RCTs) and quasirandomized controlled clinical trials (CCTs).

Types of participants-We included trials that enrolled children with PCG, diagnosed and surgically treated at or before five years of age. We used five years as the cut-off because by definition, glaucoma diagnosed after five years is classified as juvenile glaucoma (Stamper 2009). We included trials in which children diagnosed both before and after the age of five years were included when data for the subgroup of children under five years were reported separately. We excluded trials restricted to children with developmental glaucomas due to associated ocular or systemic anomalies (e.g. Peters anomaly, AxenfeldRieger syndrome) or secondary glaucomas due to surgery or trauma.

Types of interventions-We included all trials that compared any pair of surgical interventions used to treat PCG in a head-to-head design. Possible surgeries included:

1. angle surgeries, such as goniotomy, trabeculotomy, and viscocanalostomy;

2. filtering surgeries, such as trabeculectomy and deep sclerectomy;

3. surgeries using glaucoma drainage devices;

4. cyclodestructive procedures;

5. combined surgeries, such as trabeculectomy-trabeculotomy.

We also included comparisons of surgical techniques (e.g. goniotomy using a blade versus laser).

\section{Types of outcome measures}

Primary outcomes: Our primary outcome for comparison of interventions was IOP at one year after surgery. We assessed IOP as:

1. change in IOP from before surgery (baseline) to one year after surgery;

2. surgical success, defined as the proportion with postoperative IOP less than or equal to $21 \mathrm{~mm} \mathrm{Hg}$ with or without glaucoma medications at one year after surgery;

3. qualified success, defined as the proportion with postoperative IOP less than or equal to $21 \mathrm{~mm} \mathrm{Hg}$ with or without glaucoma medications after additional surgeries. 
We considered all routinely used tonometers (e.g. Goldmann applanation tonometer, pneumatonometer, Tonopen) as valid tools for measuring IOP for the purpose of the review. We also considered IOP and surgical success measured at six months and other time points when outcomes at six and 12 months postsurgery were not reported by the trial investigators. We also reported data from trials that defined surgical success in other ways.

Secondary outcomes: The secondary outcomes we specified for comparison of surgeries were as follows.

1. Visual acuity (VA) at six months and one year after surgery. We used VA at a follow-up time point rather than change in VA since most of the children enrolled in eligible trials were too young or too photophobic for VA to be measured accurately at baseline.

2. Mean change from baseline in corneal diameter at six months and one year after surgery.

3. Mean change from baseline in axial length at six months and one year after surgery.

4. Proportion of children needing repeat surgery, defined as any glaucoma surgery required in the study eye to achieve surgical success excluding corneal (e.g. penetrating keratoplasty), cataract, or retinal surgeries. Success after multiple glaucoma surgeries was considered a qualified success and not an outright surgical failure.

5. Mean number of glaucoma medications needed at six months and one year after surgery. We did not consider the use of glaucoma medications to maintain IOP as surgical failure if the IOP was less than or equal to $21 \mathrm{~mm} \mathrm{Hg}$.

6. Mean change from baseline in cup/disc ratio at six months and one year after surgery.

7. Quality of life and economic outcomes, as reported by included trials at six months and one year after surgery.

When the mean change from baseline in corneal diameter, axial length, or cup/disc ratio was not reported, and study investigators reported the data in another way (e.g. postoperative data), we also reported those data and calculated the between group difference for each outcome when their respective preoperative values were comparable between the two groups.

Adverse outcomes-We compared the proportion of children with postoperative complications between the surgery groups, including hyphema, vitreous loss, choroidal detachment, button hole, and descemet's detachment. We planned to include hypotony, bleb infections, endophthalmitis, flat chambers needing interventions, wound leak, and any other complication when reported from the included trials.

We assessed adverse outcomes within one year after surgery and anytime until the final postsurgical follow-up. 


\section{Search methods for identification of studies}

Electronic searches-We searched CENTRAL (which contains the Cochrane Eyes and Vision Group Trials Register) (The Cochrane Library 2014, Issue 6), Ovid MEDLINE, Ovid MEDLINE In-Process and Other Non-Indexed Citations, Ovid MEDLINE Daily, Ovid OLDMEDLINE (January 1946 to June 2014), EMBASE (January 1980 to June 2014), (January 1982 to June 2014), PubMed (January 1946 to June 2014), the metaRegister of Controlled Trials ( $m$ RCT) (www.controlled-trials.com), ClinicalTrials.gov (www.clinicaltrials.gov), the WHO International Clinical Trials Registry Platform (ICTRP) (www.who.int/ictrp/search/en) and the Association for Research in Vision and Ophthalmology (ARVO) conference abstracts (from February 1962 to March 7, 2013). We did not use any date or language restrictions in the electronic searches for trials. We last searched the electronic databases on 23 June 2014.

See: Appendices for details of search strategies for CENTRAL (Appendix 1), MEDLINE (Appendix 2), EMBASE (Appendix 3), PubMed (Appendix 4), mRCT (Appendix 5), ClinicalTrials.gov (Appendix 6), ICTRP (Appendix 7) and ARVO (Appendix 8).

Searching other resources-We reviewed the reference lists of the trials included in the review to identify additional candidate trials or additional reports from included trials.

\section{Data collection and analysis}

Selection of studies-The two review authors independently reviewed the titles and abstracts resulting from the literature searches and classified each article as 'definitely relevant', 'possibly relevant' or 'definitely not relevant'. We resolved any discrepancies through discussion. We then retrieved full-text reports for records labeled as 'definitely relevant' or 'possibly relevant' by both review authors. We independently assessed the fulltext reports according to the eligibility criteria and labeled them as 'included' or 'excluded'. We resolved any disagreements through discussion. For trials labeled as 'excluded', we recorded the reasons for exclusion in the 'Characteristics of excluded studies' table. For reports from trials published in languages other than English or Chinese, we used Google Translate to read the reports in English and then assessed their eligibility.

Data extraction and management-The two review authors independently extracted data related to study design and methods, participant characteristics, and primary and secondary outcomes onto forms developed by the Cochrane Eyes and Vision Group. We compared and adjudicated discrepancies with extracted data by discussion. After consensus was reached, one review author (XW) entered the data into Review Manager (RevMan) (RevMan 2014) and the second review author (DG) verified the data entered. We contacted trial investigators in an effort to retrieve incomplete or missing data (Anderson 1982; Noureddin 2006; Senft 1989), but did not receive any additional information compared with the published reports, except for information to assess risk of bias.

Assessment of risk of bias in included studies-The two review authors independently assessed the included trials for potential sources of bias according to the 
guidelines in Chapter 8 of the Cochrane Handbook for Systematic Reviews of Interventions (Higgins 2011).

We evaluated each included trial for the following potential sources of bias: selection bias (sequence generation, allocation concealment), performance bias (masking of participants and study personnel), detection bias (masking of outcome assessors), attrition bias (incomplete outcome data), reporting bias (selective outcome reporting), and other potential threats to validity. The two review authors evaluated each trial according to the abovementioned criteria and judged them as being at low, high, or unclear risk of bias. We resolved any disagreements through discussion. Whenever we judged a trial to have unclear risk of bias due to unreported information, we contacted the trial investigators (Anderson 1982; Noureddin 2006; Senft 1989). One trial investigator responded with details of randomization and we recorded that information (Anderson 1982). The other two trial investigators did not respond to our queries, so we assessed the risk of bias for their trials on the basis of the available information.

\section{Measures of treatment effect}

Dichotomous data: we calculated risk ratios (RRs) with 95\% confidence intervals (CIs) for dichotomous data.

The dichotomous outcomes of interest included surgical success and qualified success, the need for repeat glaucoma surgery, and adverse events.

Continuous data: we calculated mean differences (MDs) with 95\% CIs for outcomes based on continuous data.

Outcomes analyzed as continuous data were IOP change from before surgery, mean change from baseline in corneal diameter, mean change from baseline in axial length, mean change from baseline in cup/disc ratio, and number of medications used after primary surgery.

We planned to record visual acuity as either continuous data or dichotomous data but no such data were reported in included trials.

Unit of analysis issues-Five of six trials included both eyes of the same child in a paired-eye design; however, in none of these trials was a correct paired analysis done. We have analysed these data as reported, i.e. ignoring the paired design. This is a conservative analysis (confidence intervals will be wider than they would be if a paired analysis was done). In the sixth trial, only one eye per child was included in the trial.

Dealing with missing data-When desired data were not available, we contacted trial investigators for additional information or individual patient data, or both (Anderson 1982; Noureddin 2006; Senft 1989). When trial investigators did not respond to our queries within two weeks, we used the available data. We did not impute data for the purposes of this review. 
Assessment of heterogeneity-We assessed for clinical and methodological heterogeneity by comparing study methods, participant characteristics, and surgical interventions across trials. We planned to quantify statistical heterogeneity in meta-analyses using the $\mathrm{I}^{2}$ statistic according to the guidelines set out in Chapter 9 of the Cochrane Handbook for Systematic Reviews of Interventions (Deeks 2011).

Assessment of reporting biases-For selective outcome reporting, we compared the outcomes prespecified in the Methods section and outcomes reported in the Results section of published reports. We also planned to compare the outcomes prespecified in protocols with outcomes reported in published papers; however, we did not identify protocols for any of the included trials. For publication bias, we planned to use funnel plots created by RevMan to examine signs of asymmetry, as specified in Chapter 10 of the Cochrane Handbook for Systematic Reviews of Interventions when 10 or more included trials were included in meta-analysis (Sterne 2011).

Data synthesis-We planned to use either a fixed-effect or random-effects model for meta-analysis according to the number of trials available for inclusion in the systematic review: fixed-effect model for fewer than three trials and random-effects for three trials or more. We planned to perform data analysis according to the guidelines set out in Chapter 9 of the Cochrane Handbook for Systematic Reviews of Interventions (Deeks 2011). Due to methodological and clinical heterogeneity across trials, we did not conduct any metaanalysis.

Subgroup analysis and investigation of heterogeneity-We planned subgroup analyses for different population characteristics including age, race, ethnicity, and time from diagnosis to surgery. We also intended to conduct subgroup analyses for legally blind eyes (VA less than 20/200) and eyes with no light perception. However, we did not perform any subgroup analyses because of the small number of participants included in the trials and the absence of multiple trials that compared the same pair of surgeries. Future updates of the review may include sufficient numbers of trials and trial participants for analyses by subgroups. Individual patient data will be needed from the trial investigators when trial findings have not been reported by subgroups.

Sensitivity analysis-We planned to evaluate the impact of excluding trials with high risk of bias (specifically with respect to attrition bias and reporting bias), unpublished data, or industry funding in sensitivity analysis.

\section{RESULTS}

\section{Description of studies}

See: Characteristics of included studies; Characteristics of excluded studies; Characteristics of ongoing studies.

Results of the search-We conducted electronic searches on 23 June 2014 which yielded a total of 1340 titles and abstracts and 169 records from trial registers. After removing 39 duplicates, we screened 1470 unique records and determined that 24 were 
potentially relevant to the scope of the review. We examined the full-text reports of these 24 records and excluded 15 trials, included five trials, and listed the remaining four trials as ongoing. Through review of the reference lists of the included trials, we found an additional trial that met our inclusion criteria (Anderson 1982). Therefore, we included a total of six trials; the study flow diagram is in Figure 1.

Included studies-We included six trials in this review. Two of the six trials were CCTs (Biedner 1998; Catalano 1989), and the other four were RCTs (Anderson 1982; Bayoumi 2012; Noureddin 2006; Senft 1989). We described the details of each trial in the 'Characteristics of included studies' table. We also listed comparisons across the included trials in Table 1.

Types of participants: Four of the six trials were conducted in the Middle East (one trial each in Egypt, Israel, Lebanon, and Saudi Arabia) and two trials were conducted in the USA. There was a total of 61 children (102 eyes) enrolled in the six trials (range of 7 to 20 children per trial); all children were younger than five years of age. The inclusion criteria for the five trials with paired-eye designs was children with bilateral congenital glaucoma. The sixth trial included one eye of each child diagnosed with bilateral congenital glaucoma (Bayoumi 2012). Two trials also had IOP level as an inclusion criterion: Noureddin 2006 included children with IOP > $21 \mathrm{~mm} \mathrm{Hg}$ and Senft 1989 included children with IOP $\geq 23$ $\mathrm{mm} \mathrm{Hg}$.

Types of interventions: The interventions compared varied among the six trials and no two trials compared the same surgical procedures. Of the five trials with paired-eye designs, Anderson 1982 compared trabeculotomy in one eye versus goniotomy in the other eye of the same child at the same time; Biedner 1998 compared trabeculotomy-trabeculectomy combined procedure with trabeculotomy alone; Catalano 1989 compared one goniotomy versus two goniotomies; Noureddin 2006 compared trabeculotomy versus viscocanalostomy; and Senft 1989 compared surgical goniotomy under general anesthesia versus neodymium-YAG laser goniotomy under oral chloral hydrate sedation. Bayoumi 2012 compared combined trabeculectomy-trabeculotomy with MMC (CTTM) versus CTTM with deep sclerectomy (CTTM-DS).

\section{Types of outcomes}

Primary outcomes: Of the six trials, three reported our primary outcome of change in IOP: Bayoumi 2012 reported the percentage change in IOP from baseline to six months and one year; Noureddin 2006 reported mean change in IOP from baseline to six months follow-up; and Senft 1989 reported mean change in IOP from baseline to last follow-up (range 2 to 15 months). Another trial, Catalano 1989, reported postoperative IOP at one month follow-up. The other three trials did not report IOP outcomes.

All trials reported some measure of surgical success outcomes and three reported qualified success outcomes (Anderson 1982; Biedner 1998; Catalano 1989). The follow-up time across trials ranged from 6 to 35 months. 
Secondary outcomes: None of the trials reported any secondary outcomes as defined for our review. For outcomes to be assessed as mean changes (e.g. corneal diameter, axial length, and cup/disc ratio), only postoperative values were reported. Three trials reported postoperative corneal diameter at various time points (Bayoumi 2012; Noureddin 2006; Senft 1989); two trials reported postoperative cup/disc ratio at various time points (Bayoumi 2012; Senft 1989); and one trial reported postoperative axial length at six months and one year (Bayoumi 2012).

We did not find information about any other prespecified outcomes of interest in these included trials, i.e. VA, need for repeat surgeries, number of glaucoma medications needed, quality of life and economic outcomes.

Adverse outcomes: Investigators of four trials reported complications during follow-up (Bayoumi 2012; Biedner 1998; Noureddin 2006; Senft 1989).

Excluded studies-We excluded 15 studies after review of full-text reports and listed the reasons of exclusion in the 'Characteristics of excluded studies' table. Three studies were not RCTs (retrospective studies or case series); three studies focused on conditions other than PCG; and nine studies included children with multiple diagnoses and did not separate children diagnosed with PCG or included children with a wide age range and did not separate children aged under five years.

\section{Risk of bias in included studies}

We described the risk of bias for all six trials in detail (see the 'Characteristics of included studies' table). A summary of risk of bias assessments is shown in Figure 2.

Allocation-Of the six trials, three employed an adequate method for random sequence generation; therefore, we assessed them at low risk of bias (Anderson 1982; Bayoumi 2012; Noureddin 2006). One trial report (Senft 1989) did not specify the method for allocation sequence generation, so we judged the risk of bias to be unclear. Two CCTs did not employ an unbiased allocation method so we judged the risk of bias to be high in these trials.

We judged four trials (Anderson 1982; Bayoumi 2012;Noureddin 2006; Senft 1989) at low risk of bias as adequate procedures for allocation concealment had been employed. Three trials (Anderson 1982; Noureddin 2006; Senft 1989) had a paired-eye design, in which the two eyes of the same participant were allocated to the two surgeries at the same time, resulting in low risk of selection bias. One trial used a parallel-group design (Bayoumi 2012) in which assignment to a surgical procedure occurred intraoperatively, so allocation was always concealed until time of randomization.

We judged two CCTs (Biedner 1998; Catalano 1989) with paired-eye designs to be at high risk of bias, as the allocation of treatments was not concealed.

Masking of participants and personnel (performance bias)-None of the trials reported information on masking of participants, but considering participants were all young 
children or infants, we judged that the lack of participant masking would not lead to any performance bias. Due to the nature of the trials, surgeons could not be masked during the surgery. One trial followed standard surgical protocols (Anderson 1982). Another trial (Bayoumi 2012) carried out randomization intraoperatively in order to avoid surgeon bias in changing the thickness of the scleral flap created during the initial part of the surgery, e.g. making it thinner in cases in which deep sclerectomy was planned and thicker (deeper dissection) in cases without deep sclerectomy. We judged both of these trials to be at low risk of bias. For the other four trials, due to insufficient information, we judged them as having unclear risk of bias.

Masking of outcome assessment (detection bias)-We judged one trial (Senft 1989) at low risk of bias because the personnel who assessed IOP were masked. For the other five trials, due to insufficient information, we judged them as unclear risk of bias.

Incomplete outcome data-We judged three trials to have low risk of attrition bias: Biedner 1998 and Catalano 1989 had all or most children examined at one year; Noureddin 2006 reported six months as the primary outcome and had all children followed-up at six months. One trial had two of nine children lost to follow-up at one year, so we judged it to have high risk of attrition bias (Anderson 1982). The other two trials did not report the number of children examined at individual times, so we judged the risk of attrition bias as unclear (Bayoumi 2012; Senft 1989).

Selective reporting - None of the trials had protocols publicly available. One trial publication had some outcomes listed in the Methods section but failed to report these outcomes in the Results section; therefore, we judged this trial to have high risk of reporting bias (Catalano 1989). We judged the other five trials to have unclear risk of reporting bias.

Other potential sources of bias-Only one trial (Bayoumi 2012) included one eye for each child and was at low risk of other potential bias. The other five trials included both eyes of the same child in a paired-eye design, but did not consider intraperson correlation of outcomes in their analysis; we judged the risk of bias as unclear for these trials.

Effects of interventions-The investigators of none of the six trials reported betweengroup comparisons, so we calculated the MD or RR from reported group data. No two trials used the same pair of surgeries; therefore, we did not perform meta-analysis. We provide summary data for each pair of surgical comparisons below. None of the trials reported a sample size calculation nor provided a post-hoc power calculation of ability to detect or rule out a difference in outcomes between surgery procedures.

Trabeculotomy versus goniotomy-Anderson 1982 compared trabeculotomy versus goniotomy in 18 eyes of nine children. Each child was followed to a different time point, ranging from 3 to 34 months.

Primary outcomes (IOP and surgical success): Anderson 1982 did not report individual IOP data, individual follow-up times, or the duration of success in the eyes. Surgical success (IOP control after one surgery) was $66.7 \%$ in both trabeculotomy and goniotomy groups at 
the last follow-up examination (range 3 to 34 months); however, the definition of surgical success was not provided in the paper. The failures which occurred were bilateral failures (three children with bilateral failures). We contacted the authors for their definition of surgical success and received the following response, "the criterion was simply the usual clinical decision that the glaucoma was controlled by standard examination, including such things as resolution of corneal edema, filling in or stabilization of cupping, low (normalized) IOP under anesthesia, etc. I believe that successful cases did not require medication, and at least did not need another operation."

Qualified success (surgical success after multiple surgeries) was seen in 3/9 eyes. The six eyes of three children with surgical failure underwent second procedures; one eye needed a third procedure to achieve IOP control. The details of the secondary procedures performed and the duration after the first surgery were not mentioned in the paper.

Secondary outcomes: The trial did not report any secondary outcomes specified for this review.

Adverse outcomes: The trial did not report adverse outcomes.

\section{Combined trabeculectomy-trabeculotomy with MMC (CTTM) versus combined trabeculectomy-trabeculotomy with MMC with deep sclerectomy (CTTM-DS)-} Bayoumi 2012 compared CTTM versus CTTM-DS. The trial enrolled 20 eyes of 20 children, but did not report numbers of children examined at each time point (all children had at least six months follow-up). Thus, we do not know how many children or eyes contributed to each outcome reported. We used the number of children followed at six months (all children) for analyzing data at both 6 and 12 months, so the data at 12 months needs to be interpreted with caution.

Primary outcomes (IOP and surgical success): There was no difference between the percentage reduction in IOP from baseline between the two groups. The percentage reduction of IOP was $63 \%$ (standard deviation (SD): 24\%) for the CTTM group and 62\% (SD: $22 \%$ ) for the CTTM-DS group at 6 months (MD 1\%; 95\% CI -19.2\% to $21.2 \%$ ); and 69\% (SD: 16\%) for the CTTM group and 62\% (SD: 36\%) for the CTTM-DS group at 12 months (MD 7\%; 95\% CI $-17.4 \%$ to $31.4 \%$ ). Surgical success after one surgery at 12 months was reported as $100 \%$ for both groups (RR 1.00; 95\% CI 0.83 to 1.20), where surgical success was defined as an IOP of $<16 \mathrm{~mm} \mathrm{Hg}$ under general anesthesia with no hypotony complications or no progression of the disease (i.e. no progression in corneal diameter, cup/disc ratio and axial length), or both.

\section{Secondary outcomes}

Corneal diameter: While the preoperative corneal diameters between the two groups were comparable (MD $-0.2 \mathrm{~mm} ; 95 \% \mathrm{CI}-0.96$ to 0.56 ), we calculated and did not find any difference between the two groups at six months: mean corneal diameter was measured as $12.7 \mathrm{~mm}$ for the CTTM group and $12.5 \mathrm{~mm}$ for the CTTM-DS group (MD $0.2 \mathrm{~mm}$; $95 \%$ CI -0.52 to 0.92 ). At 12 months, the mean corneal diameter measurement for the CTTM group 
$(12.6 \mathrm{~mm})$ was greater than the CTTM-DS group $(12.0 \mathrm{~mm})(\mathrm{MD} 0.6 \mathrm{~mm}$; $95 \% \mathrm{CI} 0.01$ to 1.19). The normal range is $9.5 \mathrm{~mm}$ to $12 \mathrm{~mm}$ for children up to two years of age.

Axial length: While the preoperative values between the two groups were comparable (MD $-1.1 \mathrm{~mm} ; 95 \% \mathrm{CI}-2.37$ to 0.17 ), we calculated and did not find any difference between the two groups at six months nor one year. The lengths were $22.06 \mathrm{~mm}$ and $23.06 \mathrm{~mm}$ at six months (MD $-1.0 \mathrm{~mm} ; 95 \% \mathrm{CI}-2.12$ to 0.12 ), and $22.52 \mathrm{~mm}$ and $22.26 \mathrm{~mm}$ at 12 months (MD $0.26 \mathrm{~mm} ; 95 \% \mathrm{CI}-0.88$ to 1.40 ) for the CTTM and CTTM-DS groups, respectively. Normal axial length at 12 months is about $20 \mathrm{~mm}$.

Cup/disc ratio: While the preoperative cup/disc ratios between the two groups were comparable (MD 0.1; $95 \%$ CI -0.08 to 0.28 ), we calculated and did not find any difference between the two groups at six months: cup/disc ratios were 0.3 for the CTTM group and 0.2 for the CTTM-DS group (MD 0.1; 95\% CI -10.12 to 0.32). At 12 months, the cup/disc ratio for the CTTM group $(\mathrm{C} / \mathrm{D}$ ratio $=0.2)$ was greater than that for the CTTM-DS group $(\mathrm{C} / \mathrm{D}$ ratio $=0)(\mathrm{MD} 0.2 ; 95 \% \mathrm{CI} 0.11$ to 0.29$)$. The normal range is 0 to 0.2 for children up to two years of age.

Other secondary outcomes: The trial did not report other secondary outcomes specified for this review.

Adverse outcomes: The trial reported that two eyes (20\%) in the CTTM-DS group developed hypotonus disc edema during the first two months after surgery that resolved spontaneously thereafter (RR 5.00; 95\% CI 0.27 to 92.62). No other complications were noted in either group.

Combined trabeculotomy-trabeculectomy versus trabeculotomy-Biedner 1998 compared combined trabeculotomy-trabeculectomy versus trabeculotomy in 14 eyes of 7 children enrolled. All children completed six months follow-up. Six of the seven children completed at least 12 months follow-up. However, the trial investigator did not report outcomes by time point(s).

Primary outcomes (IOP and surgical success): The trial investigators did not find any difference between surgery arms with respect to change in IOP from preoperative levels; no average IOP was calculated because all seven children were followed for different lengths of time, ranging from 6 to 80 months. Six of seven eyes (86\%) in the combined surgery group and 4/7 (57\%) eyes in the trabeculotomy only group were reported to have achieved surgical success (IOP $\leq 21 \mathrm{~mm} \mathrm{Hg}$ after one surgery) at the end of the follow-up period of each child (RR $1.50 ; 95 \%$ CI 0.74 to 3.05 ).

All four of the eyes that failed (one in the combined surgery group and three in the trabeculotomy group) subsequently underwent trabeculectomy with MMC with "good results" per the authors. Qualified success (IOP control after multiple surgeries) was seen in all eyes undergoing additional surgery. The time interval between the first and second surgery and the duration of follow-up were not mentioned in the paper. 
Secondary outcomes: The trial did not report any secondary outcomes specified for this review.

Adverse outcomes: The trial investigators reported several adverse outcomes in the combined trabeculotomy-trabeculectomy group: one eye had choroidal detachment, two eyes had a shallow anterior chamber, and four eyes had flat diffuse filtering blebs. The investigators did not report any adverse outcomes for the trabeculotomy group except that all eyes had benign hyphema that caused no additional problems.

One goniotomy versus two goniotomies-Catalano 1989 compared one goniotomy versus two separate goniotomies performed during the same surgery. The trial enrolled 14 eyes of seven children. All children were examined at 12 months follow-up.

Primary outcomes (IOP and surgical success): Mean postoperative IOP at one month was $18.8 \mathrm{~mm} \mathrm{Hg}(\mathrm{SD}=8.0 \mathrm{~mm} \mathrm{Hg}$ ) for the one goniotomy group and $16.1 \mathrm{~mm} \mathrm{Hg}(\mathrm{SD}=4.4$ $\mathrm{mm} \mathrm{Hg}$ ) for the two goniotomies group. No data were available to compare IOP change from baseline and between surgery groups at six or 12 months after surgery.

The trial investigators reported that 5/7 eyes in the one goniotomy group and 4/7 eyes in the two goniotomies group achieved surgical success (IOP control after one surgery) at 12 months (RR 1.25; 95\% CI 0.56 to 2.77). The IOP range specified for surgical success was not reported.

The two eyes in the one goniotomy group that had unsuccessful surgery had subsequent surgical success with an additional goniotomy. One of three eyes in the two goniotomies group that had unsuccessful surgery achieved surgical success after two subsequent surgeries (one goniotomy and then a trabeculectomy with MMC). The time interval between the first and second surgery and the duration of follow-up were not mentioned in the paper.

Secondary outcomes: None of the secondary outcomes specified for this review was reported.

Adverse outcomes: The trial did not report adverse outcomes.

Trabeculotomy ab externo versus viscocanalostomy-Noureddin 2006 compared trabeculotomy versus viscocanalostomy among 16 eyes of eight children enrolled. All eight children completed at least 10 months follow-up, and five children completed one year follow-up.

Primary outcomes (IOP and surgical success): The mean decrease in IOP from baseline to six months after surgery was reported to be $20.5 \mathrm{~mm} \mathrm{Hg}$ for the trabeculotomy group and $17.1 \mathrm{~mm} \mathrm{Hg}$ for the viscocanalostomy group (MD $3.4 \mathrm{~mm} \mathrm{Hg}$; 95\% CI -3.41 to 10.21). The trial investigators reported that no pressure-lowering drugs were needed in any participant postoperatively, implying surgical success after one surgery at last follow-up examination for all eyes in both the viscocanalostomy and trabeculotomy groups (RR 1.00; 95\% CI 0.89 to 1.12). However, surgical success was not defined explicitly. 


\section{Secondary outcomes}

Corneal diameter: The decrease in vertical corneal diameter from baseline to after surgery was $0.43 \mathrm{~mm}$ for the trabeculotomy group and $0.37 \mathrm{~mm}$ for the viscocanalostomy group (MD $0.06 \mathrm{~mm}$; $95 \% \mathrm{CI}-0.46$ to 0.58 ); the decrease in horizontal corneal diameter was 0.75 $\mathrm{mm}$ for the trabeculotomy group and $0.62 \mathrm{~mm}$ for the viscocanalostomy group (MD 0.13 $\mathrm{mm} ; 95 \% \mathrm{CI}-0.41$ to 0.67$)$. However, the postoperative time point at which corneal diameter was measured was not reported.

Other secondary outcomes: The trial did not report other secondary outcomes specified for this review, i.e. VA, axial length, need for repeat surgeries, cup/disc ratio, quality of life, or economic outcomes.

Adverse outcomes: Hyphema was the most common complication, seen in 4/8 trabeculotomy eyes and $3 / 8$ viscocanalostomy eyes. One participant each had vitreous loss and choroidal detachment in the trabeculotomy group and one participant each had a button hole and descemet's detachment in the viscocanalostomy group.

\section{Surgical goniotomy under general anesthesia versus neodymium-YAG laser goniotomy under oral chloral hydrate sedation-Senft 1989 compared surgical} goniotomy under general anesthesia versus neodymium-YAG laser goniotomy under oral chloral hydrate sedation. The trial enrolled 20 eyes of 10 children, but the investigators did not report numbers of children examined at each follow-up time point.

Primary outcomes (IOP and surgical success): The mean decrease in IOP from baseline to the last postoperative follow-up examination was reported to be $4.8 \mathrm{~mm} \mathrm{Hg}$ for the surgical goniotomy group and $6.4 \mathrm{~mm} \mathrm{Hg}$ for the laser goniotomy group (MD $-1.6 \mathrm{~mm} \mathrm{Hg}$; $95 \%$ CI -12.35 to 9.15 ). The time points at which IOP was measured were not reported.

The trial investigators defined surgical success as IOP $\_2 \mathrm{~mm} \mathrm{Hg}$ or IOP reduction $>25 \%$ and reported that success was achieved in $40 \%$ of eyes (4/10) in both the surgical and laser goniotomy groups. Using our definition of surgical success (IOP $\leq 21 \mathrm{~mm} \mathrm{Hg}$ after one surgery), the proportion of eyes with surgical success was $30 \%$ (3/10 eyes) in both the groups (RR $1.00 ; 95 \%$ CI 0.26 to 3.81 ).

\section{Secondary outcomes}

Corneal diameter: The average postoperative corneal diameter was $13.5 \mathrm{~mm}$ horizontally for surgically treated eyes and $13.1 \mathrm{~mm}$ for laser-treated eyes, and remained stable throughout the trial for both groups. No SDs or time points were reported and the trial investigators did not report whether this difference between the two groups was statistically significant.

Cup/disc ratio: The trial investigators reported that the postoperative cup/disc ratio averaged 0.53 and 0.51 for the surgical and laser groups, respectively. No SDs or time points were reported and the trial investigators did not report whether this difference between the two groups was statistically significant. 
Other secondary outcomes: The trial did not report any other secondary outcomes targeted: VA, axial length, need for repeat surgeries, number of glaucoma medications needed, quality of life, or economic outcomes.

Adverse outcomes: The trial described several complications, but none of them were clinically significant: "Localized, self-limited intraocular hemorrhage was noted for both surgical and laser procedures. No patient in the surgical group had a significant hyphema during the procedure or postoperatively. Bleeding in the laser treated eyes was observed occasionally and was always insignificant". There was no reported evidence that one group had more adverse outcomes than the other.

\section{DISCUSSION}

\section{Summary of main results}

There is insufficient evidence from randomized or quasi-randomized clinical trials to determine whether any particular surgical technique is superior to another for PCG. No two of the six RCTs/CCTs on the topic compared the same pair of surgeries, limiting our ability to synthesize the findings. Further, the small number of children in each trial (range 7 to 20) may be insufficient to detect differences between study procedures. The two most common adverse events reported across all studies were hyphema ( 7 eyes) and flat diffuse filtering blebs (4 eyes).

\section{Overall completeness and applicability of evidence}

We included only trials that enrolled infants and children with PCG. PCG is a rare disease; thus, it can be difficult to identify and enroll a sufficient number of children in an RCT designed to compare different approaches in management at a single center. None of the currently included trials performed calculation of sample size, weakening the power and applicability of the evidence. We excluded trials that compared surgeries among children with secondary childhood glaucomas from the review because the treatment and prognosis of secondary glaucomas are different from PCG (Kargi 2006). We also excluded trials of children greater than five years at diagnosis. Children under five years old develop buphthalmos which results in altered anatomy and a different surgical prognosis from children without buphthalmos (Allingham 2005a).

The trials that included goniotomy as one of the surgeries may not be applicable to advanced cases of PCG since participants eligible for goniotomy need to have a clear cornea for the procedure to be technically feasible. Presumably, participants with clear corneas tend to have mild PCG and better prognosis than advanced cases. The primary outcome measures for this review were IOP and surgical success. IOP is the primary outcome measure for most glaucoma trials, particularly in young children for whom it is difficult to assess and follow visual fields and optic nerve head cupping. We defined surgical success as IOP less than or equal to $21 \mathrm{~mm} \mathrm{Hg}$ with or without glaucoma medications after one glaucoma surgery. We adopted this definition somewhat arbitrarily based on the definitions of surgical success in the literature, including nonrandomized studies (Al-Hazmi 2005; Zhang 2009). 
Secondary outcomes specified for our review included VA, corneal diameter, axial length, need for repeat surgeries, number of glaucoma medications, cup/disc ratio, quality of life, and economic data. Postoperative axial length has been shown to correlate with postoperative IOP (Kiefer 2001).

\section{Quality of the evidence}

The overall quality of the included trials (four RCTs and two CCTs) was not satisfactory, with more than half of the domains judged as unclear due to poor reporting.

Only one trial included and analyzed one eye per participant (Bayoumi 2012); the other five trials employed paired-eye designs without reporting adequate handling of correlation between eyes. There also were various flaws related to study design, limited sample size, incomplete outcome reporting, or insufficient method for data analysis among the six trials. Due to these issues, the evidence of the effectiveness and safety of these surgical procedures remain unclear, and the applicability of the evidence is limited.

\section{Potential biases in the review process}

We minimized biases in the review process by conducting an extensive literature search (see Electronic searches section for further details). The literature search included review of the reference lists for all the articles reviewed. The two review authors performed each step of article selection and data extraction. There was a glaucoma specialist and a methodologist involved in the review process.

Many of the secondary outcomes and aspects of the primary outcomes we sought were not reported from most of the trials we reviewed.

- Anderson 1982 did not report the individual results of the nine children they operated on or IOP outcomes.

- The follow-up time was variable for the participants in five trials.

- Bayoumi 2012 was the only trial to report axial lengths; Bayoumi 2012 and Senft 1989 also reported cup/disc ratio; Bayoumi 2012, Noureddin 2006 and Senft 1989 reported data on corneal diameters.

- Of the six trials, two of them did not report any surgical complications (Anderson 1982; Catalano 1989).

- None of the trials reported on other outcome measures such as VA, need for repeat surgeries, number of glaucoma medications needed, and quality of life and economic data.

\section{Agreements and disagreements with other studies or reviews}

In the discussion that follows, we decided to include retrospective studies, since there were very few RCTs or CCTs that looked at the surgical management of PCG. For the most part, we restricted the discussion to retrospective studies that were comparative in nature and evaluated children with PCG who had surgery before five years of age. 
1) Goniotomy versus trabeculotomy-Most glaucoma specialists believe that goniotomy and trabeculotomy yield similar results (Allingham 2005a; Anderson 1982; Beck 2003; Brandt 2011; Hylton 2013; Morales 2013).

This belief is based on retrospective studies. The patient population in these studies has varying age of onset, severity of the disease and preoperative diagnosis. The surgical technique, definition of surgical success and duration of follow-up of the patients vary in these studies as well.

We found only one trial (Anderson 1982) that compared trabeculotomy and goniotomy in a RCT design. The trial investigators, who compared goniotomy in one eye with trabeculotomy in the other eye of the same children, achieved similar surgical success with both surgeries and observed that the success of goniotomy correlated with the success of trabeculotomy in the other eye, i.e. intraocular correlation of outcomes. All the failures in this trial were bilateral, which led the trial investigators to conclude that in children with clear corneas and early PCG, it is the patient rather than the type of surgery which determines the success or failure of the surgery.

We compared the findings from Anderson 1982 with those of two retrospective studies that considered goniotomy versus trabeculotomy with inclusion criteria similar to many of our inclusion criteria for this review (Table 2). Al-Hazmi 2005 was a retrospective study of children less than one year old diagnosed with PCG in Saudi Arabia. The study investigators classified the PCG cases as mild, moderate, or severe based on IOP $(<25 \mathrm{~mm} \mathrm{Hg}, 25$ to 35 $\mathrm{mm} \mathrm{Hg},>35 \mathrm{~mm} \mathrm{Hg}$ ), corneal diameter (<13 mm, 13 to $14.5 \mathrm{~mm},>14.5 \mathrm{~mm}$ ) and corneal clarity (good, fair, poor). Of the 254 goniotomy cases studied, $57 \%$ were classified as mild ( $81 \%$ success rate) and $42 \%$ were classified as moderate (13\% success rate); there were no severe cases. Of the 418 trabeculotomy cases studied, 24\% were classified as mild (90\% success rate), $39 \%$ were classified as moderate (40\% success rate) and $37 \%$ were classified as severe (10\% success rate). Asseman 1972 was a retrospective study which looked at goniotomies and trabeculotomies performed in different time periods. The investigators of that study found surgical success rates of $100 \%$ with the trabeculotomies (37\% loss to follow-up) versus a $62 \%$ surgical success rate with goniotomy (no loss to follow-up at one year).

Mendicino 2000 compared the technique of 360 trabeculotomy (6-0 prolene suture) with goniotomy in a retrospective study in patients with PCG less than one year of age. They found a surgical success ( $<22 \mathrm{~mm} \mathrm{Hg}$ with or without medications) of $92 \%$ after the 360 trabeculotomy at 12 months, 24 months and last follow-up. The surgical success rates of goniotomy were $80 \%, 70 \%$ and $58 \%$ at 12 months, 24 months and last follow-up, respectively. A VA score (at final follow-up) better than 20/50 was found in 79\% of patients who underwent the 360 trabeculotomy and $53 \%$ in the goniotomy group.

2) Trabeculotomy versus trabeculectomy-Success rates have been low with trabeculectomy in older studies which group several primary and secondary glaucomas together. Beauchamp 1979 reported on 25 eyes with advanced refractory pediatric glaucoma (including secondary glaucomas) and found that IOP was controlled by trabeculectomy in 
only $50 \%$ of patients. They discussed technical problems during the surgery such as the limbal distortion secondary to buphthalmos, thinner sclera which led to a higher incidence of vitreous loss and postoperative increased healing as significant barriers to success.

Antimetabolites such as 5-fluorouracil and postoperative modifications such as suture lysis are difficult in children. It is also difficult tomonitor and treat the complications of antimetabolites such as bleb leaks, shallow chambers or large choroidal detachments.

We did not find any RCTs comparing trabeculectomy with any other glaucoma procedure. Table 3 is a summary of the retrospective studies we found that compare trabeculectomy to trabeculotomy.

Autrata 2003 is a retrospective study of PCG patients where 45 eyes with trabeculectomy without MMC (enrolled before 1995) were compared with 38 eyes with trabeculotomy (all the patients enrolled after 1995). The average length of follow-up was 8.2 years in the trabeculectomy group and 4.3 years in the trabeculotomy group. Surgical success rate (defined as IOP $<21 \mathrm{~mm} \mathrm{Hg}$ with or without medication) at 2 years was $47 \%$ in the trabeculectomy group and $76 \%$ in the trabeculotomy group. Although follow-up was unequal in the two groups, good VA (better than 6/18) was seen in $74 \%$ of patients in the trabeculotomy group and $51 \%$ of patients in the trabeculectomy group.

Debnath 1989 is a retrospective study of 16 patients (30 eyes) who underwent trabeculectomy without MMC and 16 patients (31 eyes) who underwent trabeculotomy. The two groups were not equivalent: more children in the trabeculectomy group had IOP $>35$ $\mathrm{mm} \mathrm{Hg}$ and corneal diameter $>14 \mathrm{~mm}$. The surgical success rate (IOP $<16 \mathrm{~mm} \mathrm{Hg}$ without medications) at last follow-up was 54\% in the trabeculectomy group and $67 \%$ in the trabeculotomy group.

Zhang 2009 is a retrospective study from China comparing different glaucoma procedures in children with PCG. The groups were not equivalent. Trabeculotomy was the first choice and trabeculectomy with MMC was performed if the child was older than three years with corneal diameter $>14 \mathrm{~mm}$ and the cornea was cloudy. Surgical success (IOP $<21 \mathrm{~mm}$ with or without medication) was $94 \%$ at one year and $67 \%$ at three years in the trabeculectomy with MMC group, compared to $91 \%$ at one year and $87 \%$ at three years in the trabeculotomy group.

As a primary surgery, trabeculectomy with or without MMC appears to have a lower success rate than trabeculotomy.

3) Combined trabeculectomy-trabeculotomy-Combined trabeculectomytrabeculotomy is favored in the Middle East (Mullaney 1999) and India (Mandal 1999) for patients that present late, with very severe disease plus poor follow-up (Mandal 1999). Mandal 2007 analyzed 360 consecutive children (624 eyes) who underwent combined trabeculectomy-trabeculotomy without MMC. All the children had PCG, 92\% of these were primary surgeries, and the age of surgery was 32 months (range 0 to 353 months). Surgical success rate (IOP $<16 \mathrm{~mm} \mathrm{Hg}$ with or without medications) was $85 \%$ and $77 \%$ at one and three years, respectively. 
a) Combined trabeculectomy-trabeculotomy versus trabeculotomy: Our literature search revealed only one CCT that fitted our inclusion criteria (Biedner 1998). Table 4 summarizes comparative studies of PCG patients/eyes treated with combined trabeculectomytrabeculotomy versus trabeculectomy. Biedner 1998 compared the combined procedure without MMC in one eye with trabeculotomy in the other eye and found a surgical success rate (IOP $<21 \mathrm{mmHg}$ without medications) of $86 \%$ in the combined group and $57 \%$ in the trabeculotomy alone group at the last follow-up (range 6 to 80 months). Al-Hazmi 2005 is a retrospective study from Saudi Arabia that included PCG diagnosed at less than one year of age (average age 4.2 months). Surgical success rates at two years (IOP $<21 \mathrm{~mm} \mathrm{Hg}$ without medications) were $75 \%$ in the combined group and $41 \%$ in the trabeculotomy alone group. As noted above, the study investigators classified the children into mild, moderate and severe PCG. Of the 418 trabeculotomy cases studied, 24\% were classified as mild (90\% success rate), $39 \%$ were classified as moderate (40\% success rate) and $37 \%$ were classified as severe (10\% success rate). Of the 148 combined surgery cases studied, $1 \%$ were classified as mild (100\% success rate), $47 \%$ were classified as moderate ( $80 \%$ success rate) and $51 \%$ were classified as severe (70\% success rate). Zhang 2009 was a retrospective study in China. Trabeculotomy was the primary preferred procedure, the combined procedure with MMC was performed in glaucomas deemed severe (age > three years, corneal diameter $>14 \mathrm{~mm}$ ) by the study investigators if the cornea was clear and the edema was mild. Comparing the combined group to the trabeculotomy group, the IOP was higher $(33 \mathrm{~mm} \mathrm{Hg}$ versus $30 \mathrm{~mm}$ $\mathrm{Hg}$ ), but the surgical success (IOP < $21 \mathrm{~mm} \mathrm{Hg}$ with medication) was $92 \%$ at one year, $78 \%$ at three years and $62 \%$ at nine years in the combined surgery group, and $91 \%$ at one year, $87 \%$ at three years and $38 \%$ at nine years in the trabeculotomy alone group.

The studies show that the combined procedure has better results than a trabeculotomy, even when the glaucoma was more severe in the group undergoing the combined procedure. The combined procedure is a more complicated procedure which leaves the child with a bleb and all the possibilities of long term bleb complications. The studies mentioned above were not designed to look at the risk of long term surgical complications. Combined surgery may be preferable to a regular angle surgery in a population with problematic follow-ups (Mandal 2007).

b) Combined trabeculectomy-trabeculotomy versus trabeculectomy: There are no prospective studies comparing combined trabeculectomy-trabeculotomy to trabeculectomy. Table 5 shows the two retrospective studies comparing the two procedures. Elder 1994 was a prospective-retrospective study. Children with PCG less than one year of age were treated with the combined procedure and compared to historical controls who underwent primary trabeculectomy. The preoperative IOP was higher in the combined group (33 $\mathrm{mm} \mathrm{Hg}$ versus $28 \mathrm{~mm} \mathrm{Hg}$ ) and the cornea was hazier in the trabeculectomy group ( $82 \%$ versus $56 \%$ ). The surgical success rate (IOP $<21 \mathrm{~mm} \mathrm{Hg}$ without glaucoma medications) was $72 \%$ at one year and $70 \%$ at two years in the trabeculectomy group as compared to 93.5\% at one and two years in the combined group. Zhang 2009 is a retrospective study from China. The study investigators chose either trabeculectomy with MMC or the combined procedure with MMC if the child was older than three years or the corneal diameter exceeded $14 \mathrm{~mm}$. If the cornea was clear or edema was mild, the combined 
procedure was performed. If visibility was poor, trabeculectomy was performed. They found a surgical success rate (IOP $\leq 21 \mathrm{~mm} \mathrm{Hg}$ with medication) of $92 \%$ at one year, $78 \%$ at three years and $62 \%$ at nine years in the combined group, and $94 \%$ at one year, $67 \%$ at three years and $54 \%$ at nine years in the trabeculectomy group.

The combined procedure appears to have a better surgical success rate than just the trabeculectomy alone, although in both of the studies it could be argued that the children who underwent trabeculectomy had worse glaucoma (since they had more corneal haze) than the children who underwent the combined procedure.

c) Combined trabeculectomy-trabeculotomy versus combined trabeculectomytrabeculotomy with deep sclerectomy: Our literature search revealed one RCT that compared these two procedures (Bayoumi 2012). The authors used MMC in both the arms of the study and had a $100 \%$ surgical success rate with both procedures at one year. The corneal diameter and the cup/disc ratio were similar preoperatively and at six months in the two groups. Both the corneal diameter and cup/disc ratio decreased at one year in both groups, with a larger decrease in the deep sclerectomy group. Since there was a decrease in both groups, the difference is not clinically relevant, especially considering that the axial length and IOP were not different in both groups at any time point.

4) Other glaucoma surgeries-Other surgeries that have been compared in CCTs include different goniotomy techniques. Catalano 1989 was a small study that compared one goniotomy with two simultaneous goniotomies and found no difference in outcomes. Senft 1989 compared surgical goniotomy with Nd-YAG goniotomy and found no difference in surgical success between the two.

Noureddin 2006 in a small RCT showed that viscocanalostomy may be as effective as trabeculotomy in achieving surgical success. In a recent retrospective study from China (Chen 2013), viscocanalostomy was compared to trabeculectomy with MMC. The study investigators found no significant difference in surgical success rates ( $\leq 18 \mathrm{~mm} \mathrm{Hg}$ ) at any time point. In the viscocanalostomy group, 4 eyes out of 27 were classified as failures. In the trabeculectomy group, 5 eyes out of 39 were classified as failures.

Glaucoma drainage devices are used in congenital glaucoma when the glaucoma proves refractory to angle surgery or to trabeculectomy. Our search did not yield any studies using glaucoma drainage devices as primary surgeries in PCG. Beck 2003, a retrospective study, looked at children under two years old with refractory glaucoma (primary and secondary) who had previously undergone glaucoma surgery. Aqueous shunts had an $87 \%$ success rate (IOP $<23 \mathrm{~mm} \mathrm{Hg}$ with medication) at one year as compared to a 53\% success rate with trabeculectomy with MMC. However, complication rates were high in the aqueous shunt group where 21 of 46 eyes required one or more interventions due to a complication. The most common complication was actual or near tubecornea touch (35\%). Only 3 of the 24 eyes $(12.5 \%)$ needed another surgery secondary to a complication in the trabeculectomy group. Other complications in the aqueous shunt group included cataracts (11\%) and corneal decompensation (9\%), among others. 


\section{AUTHORS' CONCLUSIONS}

\section{Implications for practice}

Our review documents the paucity of systematic research in the field of congenital glaucoma to provide reliable information about the relative benefits and risks of different surgical procedures. This is because the disease is rare and additional speciality training in the field of pediatric glaucoma surgery is required.

Surgical success rates for goniotomy versus trabeculotomy could not be adequately compared based on available data. In cases with more severe glaucoma, or with cloudy corneas, it may be technically impossible to perform a goniotomy, but a trabeculotomy could be performed. Surgical success following either procedure may be achievable with second or third surgeries.

Combined trabeculectomy-trabeculotomy is used commonly in several countries with good results, but there is a paucity of good prospective studies comparing the technique to other types of angle surgery.

\section{Implications for research}

There are considerable gaps in our knowledge of the treatment of PCG. With a multitude of surgical options available, future research should aim to address the question of which one works best. Of particular interest would be whether filtering surgeries, such as trabeculectomy, should be used in place of or in addition to angle surgeries, such as goniotomy or trabeculotomy. Considering the rarity of the disease, a multicenter, possibly international, trial may be the only way to enroll enough participants for an RCT in which several surgical approaches are compared, with stratification by PCG severity in order to provide statistically valid outcome data. One recommendation for future trials would be to include sample size calculations to ensure that the trials have sufficient power to detect differences between groups. In order to compare various surgical techniques, common outcome measures and follow-up time points should be considered when planning research on this topic. Trials should have at least one year of follow-up, preferably with primary endpoints at three to five years to establish long-term effects. Furthermore, parents of children with PCG should be involved in the design and conduct of trials, especially with regard to which outcomes are most important and meaningful to them.

\section{ACKNOWLEDGEMENTS}

We would like to thank Iris Gordon, the Trial Search Coordinator in the Cochrane Eyes and Vision Group, for developing the search strategy and conducting the electronic search for the review. We thank Sachin Kedar (SK) for assistance in preparation of the protocol of this review. We also thank the CEVG editorial group and the peer reviewers, Drs. Vikas Gulati and Barbara S. Hawkins, for their assistance and critical comments during the preparation of this review.

\section{SOURCES OF SUPPORT}

Internal sources

- $\quad$ No sources of support supplied

External sources 
- National Eye Institute, National Institutes of Health, USA.

Xue Wang is supported by the Cochrane Eyes and Vision - US Project through the National Eye Institute Grant 1 U01 EY020522

- National Institute for Health Research (NIHR), UK.

- $\quad$ Richard Wormald, Co-ordinating Editor for the Cochrane Eyes and Vision Group (CEVG) acknowledges financial support for his CEVG research sessions from the Department of Health through the award made by the National Institute for Health Research to Moorfields Eye Hospital NHS Foundation Trust and UCL Institute of Ophthalmology for a Specialist Biomedical Research Centre for Ophthalmology.

- The NIHR also funds the CEVG Editorial Base in London.

The views expressed in this publication are those of the authors and not necessarily those of the NIHR, NHS, or the Department of Health.

\section{REFERENCES}

* Indicates the major publication for the study

\section{References to studies included in this review}

Anderson DR. Discussion of paper by Quigley HA. Ophthalmology. 1982; 89(3):225-226.

Bayoumi NH. Deep sclerectomy in pediatric glaucoma filtering surgery. Eye. 2012; 26(12):15481553. [PubMed: 23060025]

Biedner BZ, Rothkoff L. Combined trabeculotomy-trabeculectomy compared with primary trabeculotomy for congenital glaucoma. Journal of Pediatric Ophthalmology and Strabismus. 1998; 35(1):49-50. [PubMed: 9503318]

Catalano RA, King RA, Calhoun JH, Sargent RA. One versus two simultaneous goniotomies as the initial surgical procedure for primary infantile glaucoma. Journal of Pediatric Ophthalmology and Strabismus. 1989; 26(1):9-13. [PubMed: 2915315]

Noureddin BN, El-Haibi CP, Cheikha A, Bashshur ZF. Viscocanalostomy versus trabeculotomy ab externo in primary congenital glaucoma: 1-year follow-up of a prospective controlled pilot study. British Journal of Ophthalmology. 2006; 90(10):1281-1285. [PubMed: 16837543]

Senft SH, Tomey KF, Traverso CE. Neodymium-YAG laser goniotomy vs surgical goniotomy. A preliminary study in paired eyes. Archives of Ophthalmology. 1989; 107(12):1773-1776. [PubMed: 2597067]

\section{References to studies excluded from this review}

Agarwal HC, Sood NN, Sihota R, Sanga L, Honavar SG. Mitomycin-C in congenital glaucoma. Ophthalmic Surgery and Lasers. 1997; 28(12):979-985. [PubMed: 9427984]

Asseman R, Corbel M, Leser C. Comparative results of trabeculotomy and goniotomy in buphthalmos [Resultats compares de la trabeculotomie et de la goniotomie chez le buphtalme]. Bulletin des Societes d'Ophtalmologie de France. 1972; 72(2):241-244.

Bohnke M, Sayar RB. Clinical results following cyclo-cryocoagulation with a nitrogen cooled probe [Klinische ergebnisse nach zyklokryokoagulation mit einer stickstoffgekuhlten sonde]. Fortschritte der Ophthalmologie: Zeitschrift der Deutschen Ophthalmologischen Gesellschaft. 1990; 87(2):134137. [PubMed: 2358267]

Colev G, Calin A, Ciglinian R. Trabeculectomy and trabeculotomy in the treatment of infantile glaucoma [Trabeculectomia si trabeculotomia in tratamentul glaucomului infantil]. Revista de Chirurgie, Oncologie, Radiologie, O. R. L., Oftalmologie, Stomatologie, Oftalmologie. 1977; 21(2):139-141.

Dascotte JC, Asseman R, Huron JC, Houliez T. Long-term results of the treatment of glaucoma in children [Resultats a long terme du traitement chirurgical du glaucome infantile]. Bulletin des Societes d'Ophtalmologie de France. 1989; 89(11):1269-1271. 
Demailly P, Kretz G. 5 Fluoro-uracil versus Daunorubicin filtering surgery in the treatment of multioperated congenital glaucoma. New Trends in Ophthalmology. 1992; 7(3):205-208.

Ding FK, Liu J, Li QY, Wang L, Hui Y, Li P. Application of sodium hyaluronate in trabeculectomy for congenital glaucoma. International Journal of Ophthalmology. 2011; 11(2):247-249.

Gimbel HV, Meyer D, DeBroff BM, Roux CW, Ferensowicz M. Intraocular pressure response to combined phacoemulsification and trabeculotomy ab externo versus phacoemulsification alone in primary open-angle glaucoma. Journal of Cataract and Refractive Surgery. 1995; 21(6):653-660. [PubMed: 8551442]

Kubota T, Takada Y, Inomata H. Surgical outcomes of trabeculotomy combined with sinusotomy for juvenile glaucoma. Japanese Journal of Ophthalmology. 2001; 45(5):499-502. [PubMed: $11583673]$

Ozcan AA, Ozdemir N, Bilgic E, Bozkurt A. Success of goniotomy and trabeculotomy as an initial procedure in the surgical treatment of congenital glaucoma. Annals of Medical Sciences. 2004; 13(3):40-43.

Plager DA, Neely DE. Intermediate-term results of endoscopic diode laser cyclophotocoagulation for pediatric glaucoma. Journal of AAPOS. 1999; 3(3):131-137. [PubMed: 10428585]

Rodrigues AM, Corpa MV, Mello PA. Comparison between trabeculectomy with mitomycin C and drainage implants in primary congenital glaucoma: a randomized study. American Academy of Ophthalmology. 2006:264.

Tamcelik N, Ozkiris A. Long-term results of viscotrabeculotomy in congenital glaucoma: comparison to classical trabeculotomy. British Journal of Ophthalmology. 2008; 92(1):36-39. [PubMed: 18156375]

Tamcelik N, Ozkiris A, Sarici AM. Long-term results of combined viscotrabeculotomytrabeculectomy in refractory developmental glaucoma. Eye. 2010; 24(4):613-618. [PubMed: 19730447]

Tamcelik N, Sarici AM, Yetik H, Ozkok A, Ozkiris A. A novel surgical technique to prevent postoperative Ahmed valve tube exposure through conjunctiva: tenon advancement and duplication. Ophthalmic Surgery, Lasers and Imaging. 2010; 41(3):370-374.

\section{References to ongoing studies}

NCT01460017. [accessed 10 September 2014] Comparison between the outcome of deep sclerectomy and traditional trabeculotomy and trabeculectomy surgeries in congenital glaucoma. clinicaltrials.gov/show/NCT01460017

NCT01494974. [accessed 10 September 2014] Comparison of the Ahmed glaucoma valve FP7 and FP8 in pediatric glaucoma: a randomized clinical trial.. clinicaltrials.gov/show/NCT01494974

NCT02121171. [accessed 11 September 2014] Comparative evaluation of combined trabeculotomytrabeculectomy versus combined trabeculotomy-trabeculectomy with subconjunctival implantation of collagen matrix implant for primary congenital glaucoma. clinicaltrials.gov/ct2/show/ NCT02121171

CTRI/2014/05/004603. Comparison of illuminated microcatheter circumferential trabeculotomy with combined trabeculotomy-trabeculectomy in primary congenital glaucoma. apps.who.int/ trialsearch/Trial2.aspx?TrialID=CTRI/2014/05/004603.

\section{Additional references}

Al-Hazmi A, Awad A, Zwaan J, Al-Mesfer SA, Al-Jadaan I, Al-Mohammed A. Correlation between surgical success rate and severity of congenital glaucoma. British Journal of Ophthalmology. 2005; 89(4):449-453. [PubMed: 15774922]

Al-Torbaq AA, Edward DP. Delayed endophthalmitis in a child following an Ahmed glaucoma valve implant. Journal of AAPOS. 2002; 6(2):123-125. [PubMed: 11997810]

Allingham, RR.; Damji, KF.; Freedman, S.; Mori, SE.; Shafranov, G., editors. Shield's Textbook of Glaucoma. 5th Edition. Philadelphia: Lippincott Williams and Wilkins; 2005. Congenital glaucoma; p. 235-252. 
Allingham, RR.; Damji, KF.; Freedman, S.; Mori, SE.; Shafranov, G., editors. Shield's Textbook of Glaucoma. 5th Edition. Philadelphia: Lippincott Williams and Wilkins; 2005. Medical and surgical treatment for childhood glaucomas; p. 623-643.

Amer SAK, Saif MYS, Saif ATS, Saif PS. Variations of cup-to-disc ratio in children. Open Journal of Ophthalmology. 2014; 4:12-17.

Anderson DR. The development of the trabecular meshwork and its abnormality in primary infantile glaucoma. Transactions of the American Ophthalmological Society. 1981; 79:458-485. [PubMed: 7342408]

Autrata R, Lokaj M. Trabeculotomy versus trabeculectomy for primary congenital glaucoma. Scripta Medica Facultatis Medicae Universitatis Brunensis Masarykianae. 2003; 76(2):79-86.

Barkan O. Techniques of goniotomy. Archives of Ophthalmology. 1938; 19:217-221.

Barkan O. Pathogenesis of congenital glaucoma: gonioscopic and anatomic observation of the angle of the anterior chamber in the normal eye and in congenital glaucoma. American Journal of Ophthalmology. 1955; 40(1):1-11. [PubMed: 14388087]

Barsoum-Homsy M, Chevrette L. Incidence and prognosis of childhood glaucoma. A study of 63 cases. Ophthalmology. 1986; 93(10):1323-1327. [PubMed: 3785892]

Beauchamp GR, Parks MM. Filtering surgery in children: barriers to success. Ophthalmology. 1979; 86(1):170-180. [PubMed: 316885]

Beck AD, Lynch MG. 360 degrees trabeculotomy for primary congenital glaucoma. Archives of Ophthalmology. 1995; 113(9):1200-1202. [PubMed: 7661757]

Beck AD, Wilson WR, Lynch MG, Lynn MJ, Noe R. Trabeculectomy with adjunctive mitomycin C in pediatric glaucoma. American Journal of Ophthalmology. 1998; 126(5):648-657. [PubMed: 9822228]

Beck AD, Freedman S, Kammer J, Jin J. Aqueous shunt devices compared with trabeculectomy with Mitomycin-C for children in the first two years of life. American Journal of Ophthalmology. 2003; 136(6):994-1000. [PubMed: 14644208]

Boger WP 3rd. Timolol in childhood glaucoma. Survey of Ophthalmology. 1983; 28(Suppl):259-261. [PubMed: 6665703]

Brandt, JD.; Suhr, AW. Surgery for Pediatric Glaucoma. In: William, Tasman; Edward, Jaeger, editors. Duane's Clinical Ophthalmology. Vol. 6. Harper and Row; 2011.

Carlsen JO, Zabriskie NA, Kwon YH, Barbe ME, Scott WE. Apparent central nervous system depression in infants after the use of topical brimonidine. American Journal of Ophthalmology. 1999; 128(2):255-256. [PubMed: 10458196]

Chen Q, Yu Y, Sun H, Zong Y, Yuan ZL. A retrospective and consecutive study of viscocanalostomy versus trabeculectomy for primary congenital glaucoma. Chinese Medical Journal. 2013; 126(8): 1418-1424. [PubMed: 23595370]

Debnath SC, Teichmann KD, Salamah K. Trabeculectomy versus trabeculotomy in congenital glaucoma. British Journal of Ophthalmology. 1989; 73(8):608-611. [PubMed: 2765438]

Deeks, JJ.; Higgins, JPT.; Altman, DG.; Higgins, JPT.; Green, S., editors. Cochrane Handbook for Systematic Reviews of Interventions Version 5.1.0. The Cochrane Collaboration; 2011. Chapter 9: Analysing data and undertaking meta-analyses. (updated March 2011). Available from www.cochrane-handbook.org.

deLuise VP, Anderson DR. Primary infantile glaucoma (congenital glaucoma). Survey of Ophthalmology. 1983; 28(1):1-19. [PubMed: 6353647]

Dorairaj SK, Bandrakalli P, Shetty C, Misquith D, Ritch R. Childhood blindness in a rural population of southern India: prevalence and etiology. Ophthalmic Epidemiology. 2008; 15(3):176-182. [PubMed: 18569813]

Elder MJ. Combined trabeculotomy-trabeculectomy compared with primary trabeculectomy for congenital glaucoma. British Journal of Ophthalmology. 1994; 78(10):745-748. [PubMed: 7803349]

Enyedi LB, Freedman SF. Latanoprost for the treatment of pediatric glaucoma. Survey of Ophthalmology. 2002; 47(Suppl 1):S129-S132. [PubMed: 12204709]

Francois J. Congenital glaucoma and its inheritance. Ophthalmologica. 1980; 181(2):61-73. [PubMed: 7219964] 
Franks W, Taylor D. Congenital glaucoma--a preventable cause of blindness. Archives of Diseases in Childhood. 1989; 64(5):649-650. [PubMed: 2499272]

Freedman SF, McCormick K, Cox TA. Mitomycin C-augumented trabeculectomy with postoperative wound modulation in pediatric glaucoma. Journal of AAPOS. 1999; 3(2):117-124. [PubMed: 10221807]

Fung DS, Roensch MA, Kooner KS, Cavanagh HD, Whitson JT. Epidemiology and characteristics of childhood glaucoma: results from the Dallas Glaucoma Registry. Clinical Ophthalmology. 2013; 7:1739-1746. [PubMed: 24039394]

Gencik A, Gencikova A, Ferák V. Population genetical aspects of primary congenital glaucoma. I. Incidence, prevalence, gene frequency, and age of onset. Human Genetics. 1982; 61(3):193-197. [PubMed: 7173860]

Gilbert CE, Canovas R, Kocksch de Canovas R, Foster A. Causes of blindness and severe visual impairment in children in Chile. Developmental Medicine and Child Neurology. 1994; 36(4):326333. [PubMed: 8157155]

Glanville JM, Lefebvre C, Miles JN, Camosso-Stefinovic J. How to identify randomized controlled trials in MEDLINE: ten years on. Journal of the Medical Library Association. 2006; 94(2):130136. [PubMed: 16636704]

Grehn F. The value of trabeculotomy in glaucoma surgery. Current Opinion in Ophthalmology. 1995; 6(2):52-60. [PubMed: 10150858]

Gutierrez-Diaz E, Montero-Rodriguez M, Mencia-Gutierrez E, Fernandez-Gonzalez MC, PerezBlazquez E. Propionibacterium acnes endophthalmitis in Ahmed glaucoma valve. European Journal of Ophthalmology. 2001; 11(4):383-385. [PubMed: 11820313]

Haas J. Principles and problems of therapy in congenital glaucoma. Investigative Ophthalmology. 1968; 7(2):140-146. [PubMed: 5641564]

Haddad MA, Sei M, Sampaio MW, Kara-José N. Causes of visual impairment in children: a study of 3,210 cases. Journal of Pediatric Ophthalmology and Strabismus. 2007; 44(4):232-240. [PubMed: 17694828]

Higgins, JPT.; Altman, DG.; Higgins, JPT.; Green, S., editors. Cochrane Handbook for Systematic Reviews of Interventions Version 5.1.0. The Cochrane Collaboration; 2011. Chapter 8: Assessing risk of bias in included studies. (updated March 2011). Available from www.cochranehandbook.org.

Hoskins HD Jr, Hetherington J Jr, Magee SD, Naykhin R, Migliazzo CV. Clinical experience with timolol in childhood glaucoma. Archives of Ophthalmology. 1985; 103(8):1163-1165. [PubMed: 4026647]

Hylton, C.; Beck, A. Congenital glaucoma and other childhood glaucomas. In: Shaarawy, T.; Sherwood, MB.; Crowston, JG.; Hitchings, RA., editors. Glaucoma Volume 1: Medical Diagnosis and Therapy. Vol. 1. Elsevier; 2013.

Kargi SH, Koc F, Biglan AW, Davis JS. Visual acuity in children with glaucoma. Ophthalmology. 2006; 113(2):229-238. [PubMed: 16406536]

Kiefer G, Schwenn O, Grehn F. Correlation of postoperative axial length growth and intraocular pressure in congenital glaucoma - a retrospective study in trabeculotomy and goniotomy. Graefe's Archive for Clinical and Experimental Ophthalmology. 2001; 239(12):893-899.

Kiskis AA, Markowitz SN, Morin JD. Corneal diameter and axial length in congenital glaucoma. Canadian Journal of Ophthalmology. 1985; 20(3):93-97. [PubMed: 4005698]

Mandal AK, Prasad K, Naduvilath TJ. Surgical results and complications of mitomycin C-augmented trabeculectomy in refractory developmental glaucoma. Ophthalmic Surgery and Lasers. 1999; 30(6):473-480. [PubMed: 10392736]

Mandal AK, Gothwal VK, Nutheti R. Surgical outcome of primary developmental glaucoma: a single surgeon's long-term experience from a tertiary eye care centre in India. Eye. 2007; 21(6):764-774. [PubMed: 16575414]

Mendicino ME, Lynch MG, Drack A, Beck AD, Harbin T, Pollard Z, et al. Long-term surgical and visual outcomes in primary congenital glaucoma: 360 degrees trabeculotomy versus goniotomy. Journal of AAPOS. 2000; 4(4):205-210. [PubMed: 10951295] 
Miller SJ. Genetic aspects of glaucoma. Transactions of the Ophthalmological Societies of the United Kingdom. 1966; 86:425-434. [PubMed: 5226587]

Morales J, Al Shahwan S, Al Odhayb S, Al Jadaan I, Edward DP. Current surgical options for the management of pediatric glaucoma. Journal of Ophthalmology. 2013; 2013 Article ID 763735.

Morin JD, Merin S, Sheppard RW. Primary congenital glaucoma - a survey. Canadian Journal of Ophthalmology. 1974; 9(1):17-28. [PubMed: 4544900]

Mullaney PB, Selleck, Al-Award A, Al-Mesfer S, Zwaan J. Combined trabeculotomy and trabeculectomy as an initial procedure in uncomplicated congenital glaucoma. Archives of Ophthalmology. 1999; 117(4):457-460. [PubMed: 10206572]

Munoz M, Tomey KF, Traverso C, Day SH, Senft SH. Clinical experience with the Molteno implant in advanced infantile glaucoma. Journal of Pediatric Ophthalmology and Strabismus. 1991; 28(2): 68-72. [PubMed: 2051291]

Olson RJ, Bromberg BB, Zimmerman TJ. Apneic spells associated with timolol therapy in a neonate. American Journal of Ophthalmology. 1979; 88(1):120-122. [PubMed: 464000]

Papadopoulos M, Cable N, Rahi J, Khaw PT. BIG Eye Study Investigators. The British Infantile and Childhood Glaucoma (BIG) Eye Study. Investigative Ophthalmology and Visual Science. 2007; 48(9):4100-4106. [PubMed: 17724193]

Passo MS, Palmer EA, Van Buskirk EM. Plasma timolol in glaucoma patients. Ophthalmology. 1984; 91(11):1361-1363. [PubMed: 6514303]

Portellos M, Buckley EG, Freedman SF. Topical versus oral carbonic anhydrase inhibitor therapy for pediatric glaucoma. Journal of AAPOS. 1998; 2(1):43-47. [PubMed: 10532366]

Quigley HA. The pathogenesis of reversible cupping in congenital glaucoma. American Journal of Ophthalmology. 1977; 84(3):358-370. [PubMed: 900230]

Quigley HA. Childhood glaucoma: results with trabeculotomy and study of reversible cupping. Ophthalmology. 1982; 89(3):219-226. [PubMed: 7088505]

The Nordic Cochrane Centre, The Cochrane Collaboration. Review Manager (RevMan). 5.3. Copenhagen: The Nordic Cochrane Centre, The Cochrane Collaboration; 2014.

Robin AL, Quigley HA. Transient reversible cupping in juvenile-onset glaucoma. American Journal of Ophthalmology. 1979; 88(3 Pt 2):580-584. [PubMed: 484688]

Sampaolesi R, Caruso R. Ocular echometry in the diagnosis of congenital glaucoma. Archives of Ophthalmology. 1982; 100(4):574-577. [PubMed: 7073567]

Sidoti PA, Belmonte SJ, Liebmann JM, Ritch R. Trabeculectomy with mitomycin-C in the treatment of pediatric glaucomas. Ophthalmology. 2000; 107(3):422-429. [PubMed: 10711876]

Sitorus RS, Abidin MS, Prihartono J. Causes and temporal trends of childhood blindness in Indonesia: study at schools for the blind in Java. British Journal of Ophthalmology. 2007; 91(9):1109-1113. [PubMed: 17709582]

Stamper, R.; Liberman, M.; Drake, M. Becker-Shaffer's Diagnosis and Therapy of the Glaucomas. 8th Edition. Mosby Elsevier; 2009. Developmental and childhood glaucoma; p. 294-329.

Sterne, JAC.; Egger, M.; Moher, D.; Higgins, JPT.; Green, S., editors. Cochrane Handbook for Systematic Reviews of Intervention. Version 5.1.0. The Cochrane Collaboration; 2011. Chapter 10: Addressing reporting biases. (updated March 2011). Available from www.cochranehandbook.org.

Taylor RH, Ainsworth JR, Evans AR, Levin AV. The epidemiology of pediatric glaucoma: the Toronto experience. Journal of AAPOS. 1999; 3(5):308-315. [PubMed: 10532577]

Thylefors B, Negrel AD. The global impact of glaucoma. Bulletin of the World Health Organization. 1994; 72(3):323-326. [PubMed: 8062393]

Waheed S, Ritterband DC, Greenfield DS, Liebmann JM, Sidoti PA, Ritch R. Bleb-related ocular infection in children after trabeculectomy with mitomycin C. Ophthalmology. 1997; 104(12): 2117-2120. [PubMed: 9400773]

Wright TM, Freedman SF. Exposure to topical apraclonidine in children with glaucoma. Journal of Glaucoma. 2009; 18(5):395-398. [PubMed: 19525731]

Zhang X, Du S, Fan Q, Peng S, Yu M, Ge J. Long-term surgical outcomes of primary congenital glaucoma in China. Clinics. 2009; 64(6):543-551. [PubMed: 19578658] 


\section{References to other published versions of this review}

Ghate D, Kedar S. Surgical interventions for primary congenital glaucoma. Cochrane Database of Systematic Reviews. 2010; (1)

\section{APPENDICES}

\section{Appendix 1. CENTRAL search strategy}

\#1 MeSH descriptor Glaucoma explode all trees with qualifier: CN

\#2 glaucoma* near/5 (congenital or neonat* or pediatric* or paediatric* or child*)

\#3 (\#1 OR \#2)

\#4 MeSH descriptor Trabeculectomy

\#5 goniotom*

\#6 trabeculotom*

\#7 trabeculectom*

\#8 trabectom*

\#9 MeSH descriptor Filtering Surgery

\#10 filtrat* near/3 (surg* or operat*)

\#11 MeSH descriptor Sclerostomy

\#12 sclerostom*

\#13 sclerectom*

\#14 viscocanalostom*

\#15 glaucoma* near/4 surg*

\#16 MeSH descriptor Glaucoma Drainage Implants

\#17 molteno or ahmed or baerveldt or krupin or schocket or joseph or optimed

\#18 glaucoma* near/6 (tube* or device* or drain* or shunt* or implant* or seton*)

\#19 MeSH descriptor Laser Coagulation

\#20 cyclophotocoagulat*

\#21 cyclocryotherap* 
\#22 (\#4 OR \#5 OR \#6 OR \#7 OR \#8 OR \#9 OR \#10 OR \#11 OR \#12 OR \#13 OR \#14 OR

\#15 OR \#16 OR \#17 OR \#18 OR \# 19 OR \#20 OR \#21)

\#23 (\#3 AND \#22)

\section{Appendix 2. MEDLINE search strategy}

1. Glaucoma/cn [Congenital]

2. ((congenital or neonat $\$$ or pediatric $\$$ or paediatric $\$$ or child\$) adj5 glaucoma $\$) . t w$.

3. or $/ 1-2$

4. exp trabeculectomy/

5. goniotom\$.tw.

6. trabeculotom $\$ . t w$.

7. trabeculectom $\$ . t w$.

8. trabectom $\$ . t w$.

9. exp filtering surgery/

10. (( $\operatorname{surg} \$$ or operat $\$)$ adj3 filtrat $\$) . t w$.

11. exp sclerostomy/

12. sclerostom $\$$.tw.

13. sclerectom $\$$.tw.

14. viscocanalostom $\$ . t w$.

15. (glaucoma $\$$ adj4 surg\$).tw.

16. exp glaucoma drainage implants/

17. (molteno or ahmed or baerveldt or krupin or schocket or joseph or optimed).tw.

18. ((tube $\$$ or device $\$$ or drain $\$$ or shunt $\$$ or implant $\$$ or seton $\$)$ adj6 glaucoma $\$) . t w$. laser coagulation/

19. cyclophotocoagulat $\$$.tw.

20. cyclocryotherap\$.tw.

21. or/4-21

22. 3 and 22

The search filter for trials at the beginning of the MEDLINE strategy is from the published paper by Glanville et al (Glanville 2006).

\section{Appendix 3. EMBASE.com search strategy}

\#1 'congenital glaucoma'/exp 
\#2 ((congenital OR neonat* OR pediatric* OR paediatric* OR child*) NEAR/5

glaucoma*):ab,ti

\#3 \#1 OR \#2

\#4 'trabeculectomy'/exp

\#5 goniotom*:ab,ti

\#6 trabeculotom*:ab,ti

\#7 trabeculectom*:ab,ti

\#8 trabectom*:ab,ti

\#9' 'filtering operation'/exp

\#10 ((surg* OR operat*) NEAR/3 filtrat*):ab,ti

\#11 'glaucoma surgery'/exp

\#12 sclerostom*:ab,ti

\#13 sclerectom*:ab,ti

\#14 viscocanalostom*:ab,ti

\#15 (glaucoma* NEAR/4 surg*):ab,ti

\#16 'glaucoma drainage implant'/exp

\#17 molteno:ab,ti OR ahmed:ab,ti OR baerveldt:ab,ti OR krupin:ab,ti OR schocket:ab,ti OR joseph:ab,ti OR optimed:ab,ti

\#18 ((tube* OR device* OR drain* OR shunt* OR implant* OR seton*) NEAR/6

glaucoma*):ab,ti

\#19 'laser coagulation'/exp

\#20 cyclophotocoagulat*:ab,ti

\#21 cyclocryotherap*:ab,ti

\#22 \#4 OR \#5 OR \#6 OR \#7 OR \#8 OR \#9 OR \#10 OR \#11 OR \#12 OR \#13 OR \#14 OR \#15 OR \#16 OR \#17 OR \#18 OR \#19 OR \#20 OR \#21

\#23 \#3 AND \#22 


\section{Appendix 4. PubMed search strategy}

\#1 (glaucoma*[tw] AND (congenital[tw] OR neonat*[tw] OR pediatric*[tw] OR

paediatric*[tw] OR child*[tw])) NOT Medline[sb]

\#2 goniotom*[tw] NOT Medline[sb]

\#3 trabeculotom*[tw] NOT Medline[sb]

\#4 trabeculectom*[tw] NOT Medline[sb]

\#5 trabectom*[tw] NOT Medline[sb]

\#6 (filtrat*[tw] AND (surg*[tw] OR operat*[tw])) NOT Medline[sb]

\#7 sclerostom*[tw] NOT Medline[sb]

\#8 sclerectom*[tw] NOT Medline[sb]

\#9 viscocanalostom*[tw] NOT Medline[sb]

\#10 (glaucoma*[tw] AND surg*[tw]) NOT Medline[sb]

\#11 (molteno[tw] OR ahmed[tw] OR baerveldt[tw] OR krupin[tw] OR schocket[tw] OR joseph[tw] OR optimed[tw]) NOT Medline[sb]

\#12 (glaucoma*[tw] AND (tube*[tw] OR device*[tw] OR drain*[tw] OR shunt*[tw] OR implant*[tw] OR seton*[tw]) NOT Medline[sb]

\#13 cyclophotocoagulat*[tw] NOT Medline[sb]

\#14 cyclocryotherap*[tw] NOT Medline[sb]

\#15 (\#2 OR \#3 OR \#4 OR \#5 OR \#6 OR \#7 OR \#8 OR \#9 OR \#10 OR \#11 OR \#12 OR \#13

OR \#14)

\#16 (\#1 AND \#15)

\section{Appendix 5. metaRegister of Controlled Trials search strategy}

(Glaucoma) AND (Congenital OR Neonatal OR Pediatric OR Paediatric OR Children) AND (Surgery OR Trabeculectomy OR Goniotomy OR Sclerostomy OR Sclerectomy OR viscocanalostomy OR Drainage OR Implant OR Ahmed OR Laser OR

Cyclophotocoagulation)

\section{Appendix 6. ClinicalTrials.gov search strategy}

(Glaucoma) AND (Congenital OR Neonatal OR Pediatric OR Paediatric OR Children) AND (Surgery OR Trabeculectomy OR Goniotomy OR Sclerostomy OR Sclerectomy OR 
viscocanalostomy OR Drainage OR Implant OR Ahmed OR Laser OR

Cyclophotocoagulation)

\section{Appendix 7. ICTRP search strategy}

Glaucoma AND Congenital OR Glaucoma AND Neonatal OR Glaucoma AND Pediatric

OR Glaucoma AND Paediatric OR Glaucoma AND Children

\section{Appendix 8. Keyword search of ARVO conference abstracts in Investigative Ophthalmology and Visual Science}

- congenital glaucoma

- pediatric glaucoma

- neonatal glaucoma

- trabeculotomy

- goniotomy

- viscocanalostomy

- trabeculectomy

- glaucoma drainage device

- Ahmed valve and pediatric glaucoma

- Baerveldt valve and pediatric glaucoma

- Molteno valve and pediatric glaucoma

- cyclocryotherapy

- transscleral cyclophotocoagulation

- endoscopic cyclophotocoagulation

- non penetrating glaucoma surgery

- non penetrating deep sclerectomy

- trabectome 


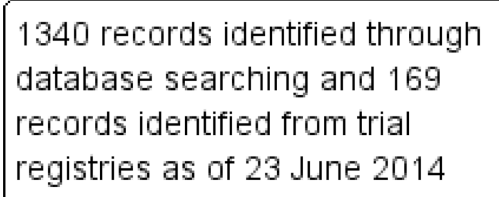

$$
\text { (2. }
$$

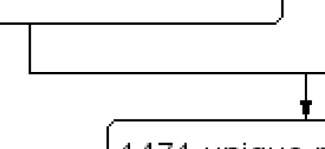

1471 unique records

after duplicates removed

1471 records screened 1446 records excluded

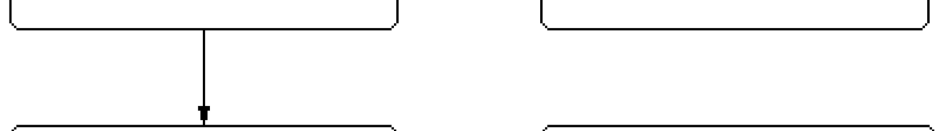

25 full-text reports assessed for eligibility 15 studies excluded,

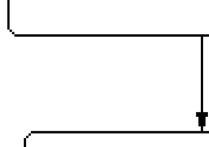

4 ongoing studies will be assessed when data becomes available

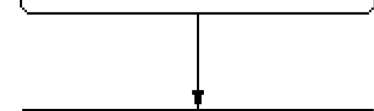
6 studies included in
the qualitative
synthesis with reasons

Figure 1.

Results from searching for studies for inclusion in the review Included studies 


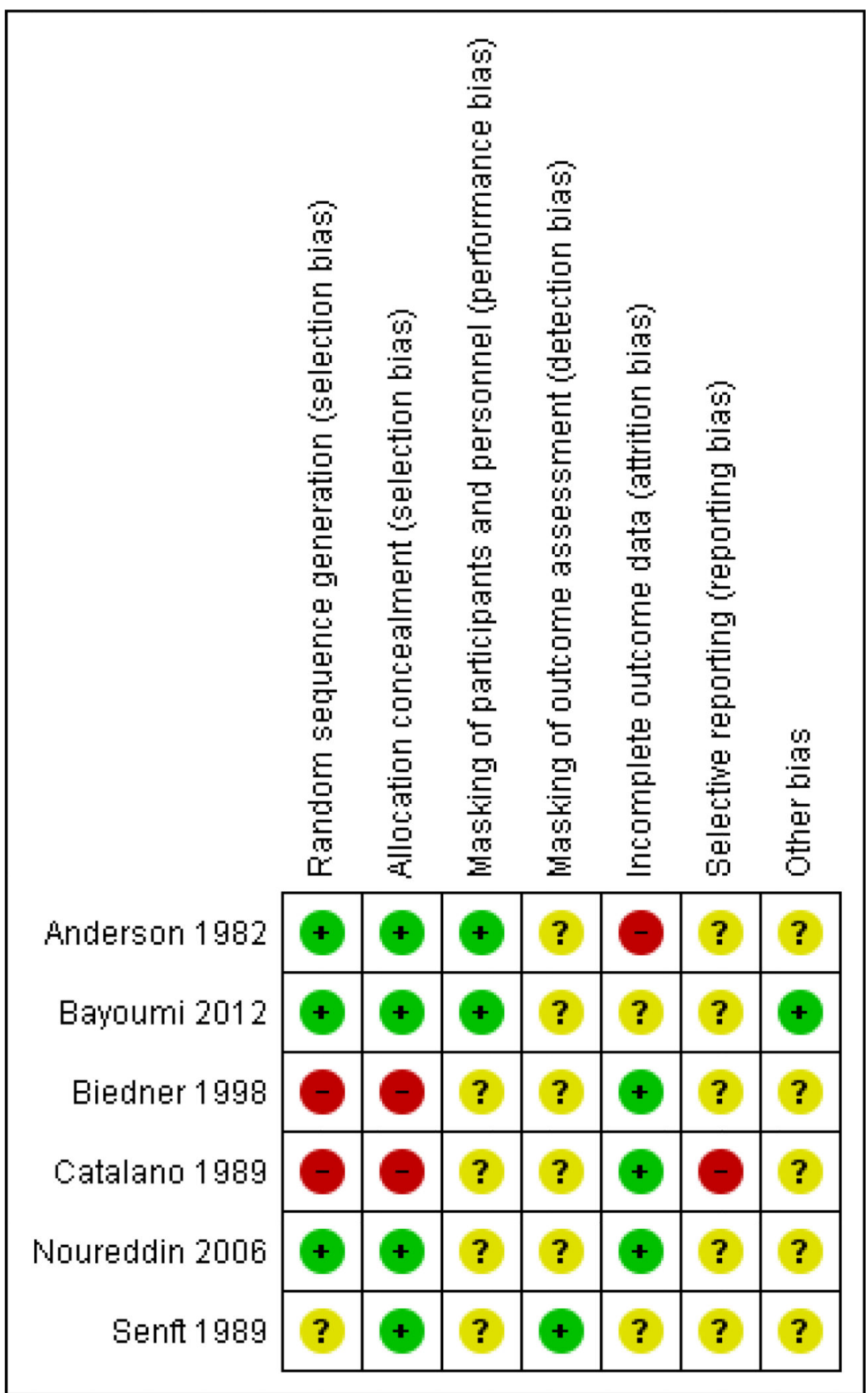

Figure 2.

Risk of bias summary: review authors' judgements about each risk of bias item for each included study. 



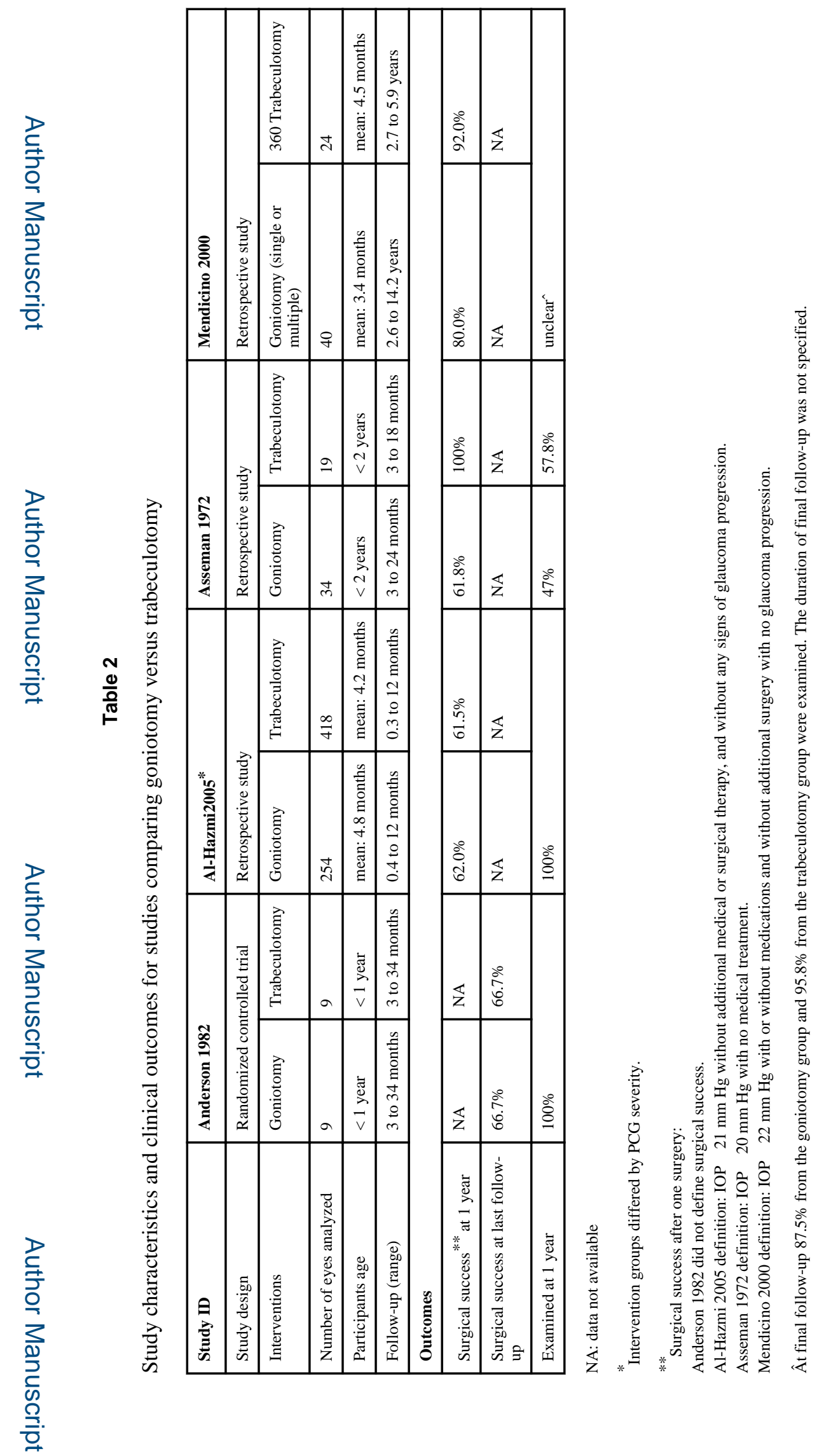

Cochrane Database Syst Rev. Author manuscript; available in PMC 2016 January 30. 


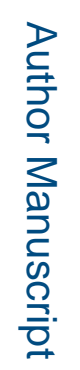
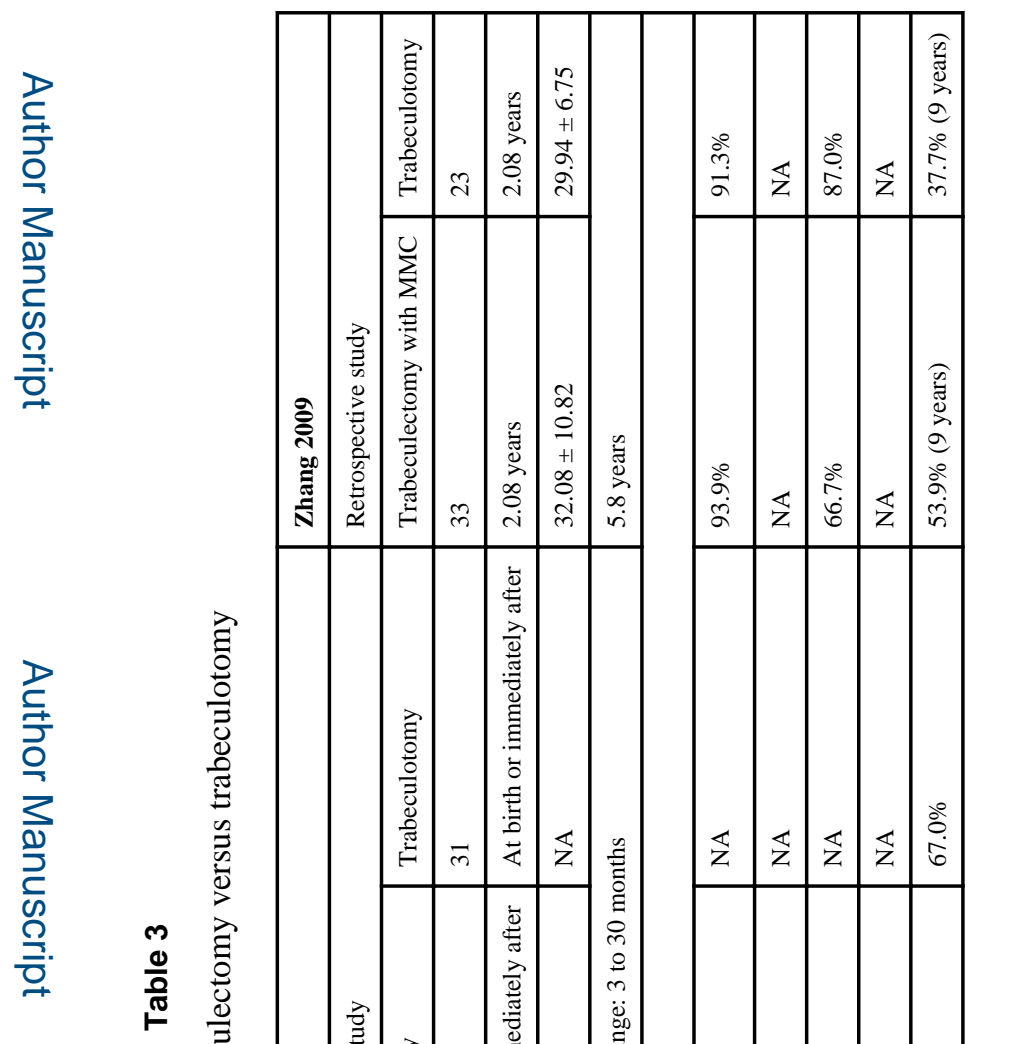

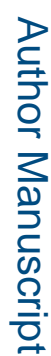

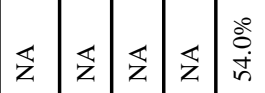

$\stackrel{0}{.}$

可

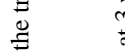

齐

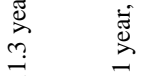

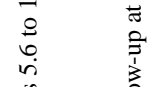

年

总尊

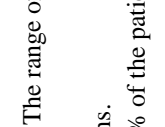

实言

造

일

五

总

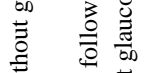

可

ज हु

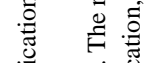

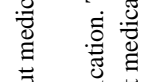

言 曾

章言

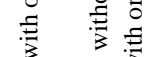

垔

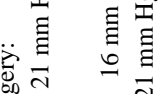

ov vi $\bar{v}$

के oิ

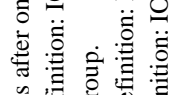

过 专

药

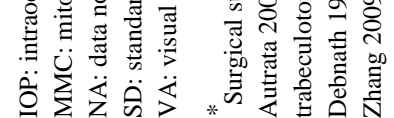


Table 4

Study characteristics and clinical outcomes for studies comparing combined trabeculectomy-trabeculotomy versus trabeculotomy

\begin{tabular}{|c|c|c|c|c|c|c|}
\hline Study ID & \multicolumn{2}{|l|}{ Biedner 1998} & \multicolumn{2}{|l|}{ Al-Hazmi $2005^{*}$} & \multicolumn{2}{|l|}{ Zhang 2009} \\
\hline Study design & \multicolumn{2}{|l|}{ Quasi-randomized trial } & \multicolumn{2}{|c|}{ Retrospective study } & \multicolumn{2}{|c|}{ Retrospective study } \\
\hline Interventions & Combined trabeculectomy-trabeculotomy & Trabeculotomy & $\begin{array}{l}\text { Combined } \\
\text { trabeculectomy- } \\
\text { trabeculotomy } \\
\text { with MMC }\end{array}$ & Trabeculotomy & $\begin{array}{l}\text { Combined } \\
\text { trabeculectomy- } \\
\text { trabeculotomy } \\
\text { with MMC }\end{array}$ & Trabeculotomy \\
\hline $\begin{array}{l}\text { Number of eyes } \\
\text { enrolled }\end{array}$ & 7 & 7 & 148 & 418 & 25 & 23 \\
\hline Participants age (mean) & 3.4 months & 4.9 months & 3.5 months & 4.2 months & \multicolumn{2}{|l|}{2.1 years } \\
\hline $\begin{array}{l}\text { Baseline IOP }(\mathrm{mm} \mathrm{Hg} \text {, } \\
\text { mean } \pm \text { SD })\end{array}$ & NA & NA & NA & NA & $32.74 \pm 8.71$ & $29.94 \pm 6.75$ \\
\hline Follow-up (mean) & \multicolumn{2}{|l|}{ range: 6 to 80 months } & 16 months & 14 months & \multicolumn{2}{|l|}{5.8 years } \\
\hline \multicolumn{7}{|l|}{ Outcomes } \\
\hline $\begin{array}{l}\text { Surgical success }{ }^{* *} \text { at } \\
\text { lyear }\end{array}$ & $\mathrm{NA}$ & NA & $87.4 \%$ & $61.5 \%$ & $92.0 \%$ & $91.3 \%$ \\
\hline $\begin{array}{l}\text { Surgical success at } 2 \\
\text { years }\end{array}$ & NA & NA & $75.0 \%$ & $41.0 \%$ & $\mathrm{NA}$ & $\mathrm{NA}$ \\
\hline $\begin{array}{l}\text { Surgical success at } 3 \\
\text { years }\end{array}$ & NA & NA & NA & NA & $78.0 \%$ & $87.0 \%$ \\
\hline $\begin{array}{l}\text { Surgical success at last } \\
\text { follow-up }\end{array}$ & $85.7 \%$ & $57.1 \%$ & $\mathrm{NA}$ & NA & $62.4 \%$ (9 years) & $37.7 \%$ (9 years) \\
\hline
\end{tabular}

C/D: cup to disk ratio

IOP: intraocular pressure

MMC: mitomycin C

NA: data not available

SD: standard deviation

*

* Intervention groups differed by PCG severity.

$* *$

Surgical success after one surgery:

Biedner 1998 definition: IOP of $\leq 20 \mathrm{~mm} \mathrm{Hg}$ without medical treatment.

Al-Hazmi 2005 definition: IOP $\_21 \mathrm{~mm} \mathrm{Hg}$ without additional medical or surgical therapy, and without any signs of glaucoma progression.

Zhang 2009 definition: IOP $\leq 21 \mathrm{~mm} \mathrm{Hg}$ with or without medication, without glaucoma progression. 100\% of the patients had follow-up at 1 year,

$79 \%$ at 3 years. 


\section{Table 5}

Study characteristics and clinical outcomes for studies comparing combined trabeculectomy-trabeculotomy versus trabeculectomy

\begin{tabular}{|c|c|c|c|c|}
\hline Study ID & \multicolumn{2}{|l|}{ Elder 1994} & \multicolumn{2}{|l|}{ Zhang 2009} \\
\hline Study design & \multicolumn{2}{|l|}{ Retrospective study } & \multicolumn{2}{|l|}{ Retrospective study } \\
\hline Interventions & Trabeculectomy-trabeculotomy & Trabeculectomy & Trabeculectomy-trabeculotomy with MMC & Trabeculectomy with MMC \\
\hline $\begin{array}{l}\text { Number of eyes } \\
\text { analyzed }\end{array}$ & 16 & 44 & 25 & 33 \\
\hline Participants age (mean) & 5.6 months & 4.3 months & \multicolumn{2}{|l|}{2.08 years } \\
\hline $\begin{array}{l}\text { Baseline IOP }(\mathrm{mm} \mathrm{Hg} \text {, } \\
\text { mean } \pm \mathrm{SD})\end{array}$ & $32.6 \pm 6.9$ & $28.4 \pm 7.4$ & $32.74 \pm 8.71$ & $32.08 \pm 10.82$ \\
\hline Follow-up (mean) & 21.6 months & 48.4 months & \multicolumn{2}{|l|}{5.8 years } \\
\hline \multicolumn{5}{|l|}{ Outcomes } \\
\hline $\begin{array}{l}\text { Surgical success } * \text { at } 1 \\
\text { year }\end{array}$ & $93.5 \%$ & $72.0 \%$ & $92.0 \%$ & $93.9 \%$ \\
\hline $\begin{array}{l}\text { Surgical success at } 2 \\
\text { years }\end{array}$ & $93.5 \%$ & $70.0 \%$ & NA & NA \\
\hline $\begin{array}{l}\text { Surgical success at } 3 \\
\text { years }\end{array}$ & NA & NA & $78.0 \%$ & $66.7 \%$ \\
\hline $\begin{array}{l}\text { Surgical success at last } \\
\text { follow-up }\end{array}$ & NA & NA & $62.4 \%$ (9 years) & $53.9 \%$ (9 years) \\
\hline
\end{tabular}

C/D: cup to disk ratio

IOP: intraocular pressure

MMC: mitomycin C

NA: data not available

SD: standard deviation

Surgical success after one surgery:

Elder 1994 definition: IOP $\leq 21 \mathrm{~mm} \mathrm{Hg}$ on no medication. Follow-up in the trabeculotomy group ranged from 3 to 110 months and 19 to 27 months in the trabeculotomy-trabeculectomy group.

Zhang 2009 definition: IOP $\leq 21 \mathrm{~mm} \mathrm{Hg}$ with or without medication, without glaucoma progression. $100 \%$ of the patients had follow-up at 1 year, $79 \%$ at 3 years. 


\section{CHARACTERISTICS OF STUDIES}

Characteristics of included studies [ordered by study ID]

\begin{tabular}{|c|c|c|}
\hline Methods & \multicolumn{2}{|c|}{$\begin{array}{l}\text { Study design: RCT, paired-eye design } \\
\text { Number randomized (total and per group): } 9 \text { children with } 18 \text { eyes; } 9 \text { eyes in the goniotomy group and } 9 \text { eyes in the } \\
\text { trabeculotomy group } \\
\text { Number analyzed (total and per group): } 9 \text { children with } 18 \text { eyes; } 9 \text { eyes in the goniotomy group and } 9 \text { eyes in the } \\
\text { trabeculotomy group. The study also reported on the results of } 23 \text { more eyes with } 16 \text { undergoing trabeculotomy and } 7 \\
\text { goniotomy. These } 23 \text { eyes were not randomized and hence were excluded from our analysis } \\
\text { Losses to follow-up: } 14 \text { eyes were followed at } 1 \text { year } \\
\text { Length of follow-up: } \\
\text { Planned: not reported } \\
\text { Actual: each participant was followed to a different time point, ranging from } 3 \text { to } 34 \text { months }\end{array}$} \\
\hline Participants & \multicolumn{2}{|c|}{$\begin{array}{l}\text { Country: USA } \\
\text { Age: less than } 9 \text { months of age } \\
\text { Gender: not specified } \\
\text { Inclusion criteria: primary bilateral infantile glaucoma, less than } 1 \text { year of age } \\
\text { Equivalence of baseline characteristics: probably equivalent, although details of glaucoma not mentioned }\end{array}$} \\
\hline Interventions & \multicolumn{2}{|c|}{$\begin{array}{l}\text { Intervention 1: trabeculotomy } \\
\text { Intervention 2: goniotomy }\end{array}$} \\
\hline Outcomes & \multicolumn{2}{|c|}{$\begin{array}{l}\text { Outcomes: surgical success (not defined) } \\
\text { Intervals at which outcome assessed: not mentioned } \\
\text { Issues with outcome assessment: IOP not mentioned as part of definition of surgical success } \\
\text { Adverse effects: not reported }\end{array}$} \\
\hline Notes & \multicolumn{2}{|c|}{$\begin{array}{l}\text { Type of study: published } \\
\text { Funding: not specified } \\
\text { Declaration of interest: not specified } \\
\text { Study period: not specified }\end{array}$} \\
\hline \multicolumn{3}{|l|}{ Risk of bias } \\
\hline Bias & Authors' judgement & Support for judgement \\
\hline $\begin{array}{l}\text { Random sequence } \\
\text { generation } \\
\text { (selection bias) }\end{array}$ & Low risk & $\begin{array}{l}\text { The study only mentioned "trabeculotomy in one eye and goniotomy in the other eye," but did } \\
\text { not mention whether it was an RCT or CCT. In an email from Dr. Anderson, he mentioned } \\
\text { that randomization was done by an unusual method: "A cotton tipped applicator was broken in } \\
\text { half, one half with cotton, the other one without. A nurse held one in her closed hand and the } \\
\text { other in her other closed hand. The surgeon chose a hand after specifying that if the one with } \\
\text { cotton were selected, he would do the goniotomy on the right eye, and if not, the goniotomy } \\
\text { would be done on the left eye. This was done long before it became common to have a } \\
\text { statistician make envelopes with one to be picked and opened with the instructions on which } \\
\text { eye was to have which procedure. Thus there were no criteria for selecting the eye to get either } \\
\text { one of the other procedure. Both eyes had to be eligible to have either procedure." } \\
\text { As the selection of hand with cotton is similar to flip of a coin, we assessed the random } \\
\text { sequence generation at low risk of bias }\end{array}$ \\
\hline $\begin{array}{l}\text { Allocation } \\
\text { concealment } \\
\text { (selection bias) }\end{array}$ & Low risk & The 2 eyes were allocated concurrently to 2 interventions. \\
\hline $\begin{array}{l}\text { Masking of } \\
\text { participants and } \\
\text { personnel } \\
\text { (performance bias) }\end{array}$ & Low risk & $\begin{array}{l}\text { The surgeons could not be masked, but surgical procedures were standardized (per Dr. } \\
\text { Anderson in a personal communication). Not masking young children/infants is unlikely to } \\
\text { introduce bias }\end{array}$ \\
\hline $\begin{array}{l}\text { Masking of } \\
\text { outcome } \\
\text { assessment } \\
\text { (detection bias) }\end{array}$ & Unclear risk & We did not know whether outcome assessors were masked. \\
\hline $\begin{array}{l}\text { Incomplete } \\
\text { outcome data } \\
\text { (attrition bias) All } \\
\text { outcomes }\end{array}$ & High risk & Fourteen of the 18 eyes were followed up at 1 year. \\
\hline $\begin{array}{l}\text { Selective reporting } \\
\text { (reporting bias) }\end{array}$ & Unclear risk & $\begin{array}{l}\text { The protocol was not available. Outcomes prespecified in the Methods section matched the } \\
\text { outcomes reported in the Results section }\end{array}$ \\
\hline
\end{tabular}




\begin{tabular}{|c|c|c|}
\hline Other bias & Unclear risk & $\begin{array}{l}\text { The study included both eyes of the same participant, but did not consider intraperson } \\
\text { correlation of outcomes }\end{array}$ \\
\hline \multicolumn{3}{|c|}{ Bayoumi 2012} \\
\hline Methods & \multicolumn{2}{|c|}{$\begin{array}{l}\text { Study design: RCT, parallel group design with } 1 \text { study eye per child } \\
\text { Number randomized (total and per group): } 20 \text { eyes of } 20 \text { children; } 10 \text { for combined trabeculectomy-trabeculotomy } \\
\text { with MMC alone (CTTM) and } 10 \text { for CTTM with deep sclerectomy (CTTM-DS) } \\
\text { Number analyzed (total and per group): all children completed at least } 6 \text { months follow-up; children analyzed at } 1 \\
\text { year were not reported } \\
\text { Losses to follow-up: all children completed at least } 6 \text { months follow-up } \\
\text { Length of follow-up: } \\
\text { Planned: not reported } \\
\text { Actual: } 18.5 \pm 9.2 \text { (range } 8 \text { to } 35 \text { ) months for the CTTM group; } 14.6 \pm 4.3 \text { (range } 6 \text { to } 20 \text { ) for the CTTM-DS group }\end{array}$} \\
\hline Participants & \multicolumn{2}{|c|}{$\begin{array}{l}\text { Country: Egypt } \\
\text { Age: CTTM group: } 4.7 \pm 2.0 \text { months; CTTM-DS group: } 7.0 \pm 3.8 \text { months } \\
\text { Gender: CTTM group: } 6 / 10(60 \%) \text { boys and } 4 / 10(40 \%) \text { girls; CTTM-DS group: } 8 / 10(80 \%) \text { boys and } 2 / 10(20 \%) \text { girls } \\
\text { Inclusion criteria: diagnosis of primary congenital glaucoma } \\
\text { Equivalence of baseline characteristics: "There were no statistically significant differences between the two groups of } \\
\text { participants as regards the preoperative variables, including age, IOP, corneal diameter, cup/disc ratio, and axial length" }\end{array}$} \\
\hline Interventions & \multicolumn{2}{|c|}{$\begin{array}{l}\text { Intervention 1: CTTM } \\
\text { Intervention 2: CTTM-DS }\end{array}$} \\
\hline \multirow[t]{7}{*}{ Outcomes } & \multicolumn{2}{|l|}{ Outcomes: } \\
\hline & $1 \quad \mathrm{I}$ & $\begin{array}{l}\text { IOP-measurements were made during an EUA with a Perkins tonometer just after induction of anesthesia } \\
\text { and before intubation }\end{array}$ \\
\hline & $2 C$ & Corneal diameter-details of measurement not given \\
\hline & 3 & $\mathrm{C} / \mathrm{D}$ ratio - details of measurement not given \\
\hline & $4 \quad A$ & Axial length \\
\hline & $5 \quad s$ & $\begin{array}{l}\text { Surgical success defined as IOP }<16 \mathrm{~mm} \mathrm{Hg} \text { with no hypotony complications and no progression of disease } \\
\text { as determined by measured ocular parameters }\end{array}$ \\
\hline & & Adverse events \\
\hline
\end{tabular}

Intervals at which outcome assessed: 1, 2, 3, 6, 9, and 12 months

Issues with outcome assessment: none

Adverse effects: yes

\begin{tabular}{l|l}
\hline Notes & $\begin{array}{l}\text { Type of study: published } \\
\text { Funding: not reported } \\
\text { Declaration of interest: "The author declares no conflict of interest" } \\
\text { Study period: not reported }\end{array}$ \\
\hline
\end{tabular}

Risk of bias

\begin{tabular}{|c|c|c|}
\hline Bias & Authors' judgement & Support for judgement \\
\hline $\begin{array}{l}\text { Random sequence } \\
\text { generation } \\
\text { (selection bias) }\end{array}$ & Low risk & $\begin{array}{l}\text { "A CTTM was conducted in all the patients. Intraoperatively, eyes were randomized for the } \\
\text { procedure of CTTM alone or with the addition of a deep sclerectomy. Randomization was } \\
\text { carried out by a flip coin choice by an attending assistant nurse. Randomization was not } \\
\text { carried out preoperatively in order to avoid surgeon bias in changing the thickness of the } \\
\text { scleral flap created during the initial part of the surgery, tending to make it thinner in cases in } \\
\text { which deep sclerectomy was planned and thicker (deeper dissection) in cases without deep } \\
\text { sclerectomy." }\end{array}$ \\
\hline $\begin{array}{l}\text { Allocation } \\
\text { concealment } \\
\text { (selection bias) }\end{array}$ & Low risk & $\begin{array}{l}\text { Since the randomization was done intra-operatively, and was determined by flip of coin, the } \\
\text { next allocation was not known }\end{array}$ \\
\hline $\begin{array}{l}\text { Masking of } \\
\text { participants and } \\
\text { personnel } \\
\text { (performance bias) }\end{array}$ & Low risk & $\begin{array}{l}\text { The surgeon could not be masked. However, the study carried out randomization } \\
\text { intraoperatively in order to avoid surgeon bias in changing the thickness of the scleral flap } \\
\text { created during the initial part of the surgery, for example, making it thinner in cases in which } \\
\text { deep sclerectomy was planned and thicker (deeper dissection) in cases without deep } \\
\text { sclerectomy. Not masking young children/infants is unlikely to introduce bias }\end{array}$ \\
\hline $\begin{array}{l}\text { Masking of } \\
\text { outcome } \\
\text { assessment } \\
\text { (detection bias) }\end{array}$ & Unclear risk & $\begin{array}{l}\text { The measurements of IOP, optic nerve cupping, corneal diameter, and axial length were all } \\
\text { done by an opthalmologist (rather than the surgeon who performed the procedure). We are not } \\
\text { aware if this person was masked }\end{array}$ \\
\hline
\end{tabular}




\begin{tabular}{|c|c|c|}
\hline $\begin{array}{l}\text { Incomplete } \\
\text { outcome data } \\
\text { (attrition bias) All } \\
\text { outcomes }\end{array}$ & Unclear risk & $\begin{array}{l}\text { All children completed at least } 6 \text { months follow-up; number of children analyzed at } 1 \text { year was } \\
\text { not reported }\end{array}$ \\
\hline $\begin{array}{l}\text { Selective reporting } \\
\text { (reporting bias) }\end{array}$ & Unclear risk Low risk & $\begin{array}{l}\text { The protocol was not available. Outcomes prespecified in the Methods section matched the } \\
\text { outcomes reported in the Results section }\end{array}$ \\
\hline Other bias & Low risk & None identified. \\
\hline \multicolumn{3}{|l|}{ Biedner 1998} \\
\hline Methods & \multicolumn{2}{|c|}{$\begin{array}{l}\text { Study design: CCT, paired-eye design } \\
\text { Number randomized (total and per group): } 7 \text { children with } 14 \text { eyes; } 7 \text { right eyes underwent the trabeculotomy- } \\
\text { trabeculectomy combined procedure and } 7 \text { left eyes underwent trabeculotomy alone } \\
\text { Number analyzed (total and per group): all children completed } 6 \text { months follow-up, } 6 / 7 \text { children completed at least } 1 \\
\text { year follow-up } \\
\text { Losses to follow-up: not reported } \\
\text { Length of follow-up: } \\
\text { Planned: a minimum of } 6 \text { months } \\
\text { Actual: } 40.29 \pm 27.96 \text { months }\end{array}$} \\
\hline Participants & \multicolumn{2}{|c|}{$\begin{array}{l}\text { Country: Israel } \\
\text { Age: trabeculotomy-trabeculectomy combined group: } 3.43 \pm 3.31 \text { weeks; trabeculotomy alone group: } 4.86 \pm 3.89 \text { weeks } \\
\text { Gender: not reported } \\
\text { Inclusion criteria: bilateral congenital glaucoma, younger than } 3 \text { months of age } \\
\text { Equivalence of baseline characteristics: each surgery was performed on the } 2 \text { eyes of the same participant. Ages at } \\
\text { time of surgery differed by design (the right eye was always operated on first, the average time interval between the } 2 \\
\text { procedures was } 1.43 \pm 1.62 \text { weeks) }\end{array}$} \\
\hline Interventions & \multicolumn{2}{|c|}{$\begin{array}{l}\text { Intervention 1: trabeculotomy-trabeculectomy combined procedure } \\
\text { Intervention 2: trabeculotomy alone }\end{array}$} \\
\hline Outcomes & \multicolumn{2}{|c|}{$\begin{array}{l}\text { Outcomes: IOP before surgery and at the end of follow-up } \\
\text { Complications during follow-up } \\
\text { Intervals at which outcome assessed: IOP was measured at the last follow-up of each participant } \\
\text { Issues with outcome assessment: none } \\
\text { Adverse effects: choroidal detachment, hyphema, shallow anterior chambers, corneal opacities, flat diffuse filtering } \\
\text { blebs }\end{array}$} \\
\hline Notes & \multicolumn{2}{|c|}{$\begin{array}{l}\text { Type of study: published } \\
\text { Funding: not reported } \\
\text { Declaration of interest: not reported } \\
\text { Study period: } 1988 \text { to } 1995\end{array}$} \\
\hline \multicolumn{3}{|l|}{ Risk of bias } \\
\hline Bias & Authors' judgement & Support for judgement \\
\hline $\begin{array}{l}\text { Random sequence } \\
\text { generation } \\
\text { (selection bias) }\end{array}$ & High risk & $\begin{array}{l}\text { "The right eye underwent the trabeculotomy-trabeculectomy combined procedure, and the left } \\
\text { eye underwent trabeculotomy alone, regardless of the IOP recorded." }\end{array}$ \\
\hline $\begin{array}{l}\text { Allocation } \\
\text { concealment } \\
\text { (selection bias) }\end{array}$ & High risk & Allocation was not concealed. \\
\hline $\begin{array}{l}\text { Masking of } \\
\text { participants and } \\
\text { personnel } \\
\text { (performance bias) }\end{array}$ & Unclear risk & $\begin{array}{l}\text { The surgeon could not be masked. Not masking young children/infants are unlikely to } \\
\text { introduce bias }\end{array}$ \\
\hline $\begin{array}{l}\text { Masking of } \\
\text { outcome } \\
\text { assessment } \\
\text { (detection bias) }\end{array}$ & Unclear risk & We did not know whether outcome assessors were masked. \\
\hline $\begin{array}{l}\text { Incomplete } \\
\text { outcome data } \\
\text { (attrition bias) All } \\
\text { outcomes }\end{array}$ & Low risk & 6 out of 7 children completed 1 year follow-up. \\
\hline $\begin{array}{l}\text { Selective reporting } \\
\text { (reporting bias) }\end{array}$ & Unclear risk & $\begin{array}{l}\text { The protocol was not available. Outcomes prespecified in the Methods section matched the } \\
\text { outcomes reported in the Results section }\end{array}$ \\
\hline Other bias & Unclear risk & $\begin{array}{l}\text { The study included both eyes of the same participant, but did not consider intraperson } \\
\text { correlation of outcomes }\end{array}$ \\
\hline
\end{tabular}


Catalano 1989

\begin{tabular}{|c|c|c|}
\hline Methods & \multicolumn{2}{|c|}{$\begin{array}{l}\text { Study design: CCT, paired-eye design } \\
\text { Number randomized (total and per group): } 7 \text { children with } 14 \text { eyes; } 7 \text { eyes had } 2 \text { separate goniotomies (either the } \\
\text { worse eye or randomized), } 7 \text { eyes had only } 1 \text { goniotomy } \\
\text { Number analyzed (total and per group): all eyes examined at } 1 \text { year } \\
\text { Losses to follow-up: participants were followed at different time points; all eyes examined at } 1 \text { year } \\
\text { Length of follow-up: } \\
\text { Planned: minimum } 12 \text { months } \\
\text { Actual: } 12 \text { months }\end{array}$} \\
\hline Participants & \multicolumn{2}{|c|}{$\begin{array}{l}\text { Country: USA } \\
\text { Age: } 4.5 \pm 2.9 \text { months at diagnosis (range } 1.5 \text { to } 10.5 \text { months) } \\
\text { Gender: not reported } \\
\text { Inclusion criteria: bilateral primary congenital glaucoma } \\
\text { Exclusion criteria: corneal edema or enlargement without glaucoma, or both, due to birth trauma; corneal dystrophy; } \\
\text { metabolic storage disorder; and infants with glaucoma associated with easily recognized abnormalities of the iris, such } \\
\text { as aniridia or iridocorneal dysgenesis } \\
\text { Equivalence of baseline characteristics: no; the more severely affected eye was chosen for the } 2 \text { goniotomies } \\
\text { procedure in } 1 \text { of the study sites (Wills Eye Hospital) }\end{array}$} \\
\hline Interventions & \multicolumn{2}{|c|}{$\begin{array}{l}\text { Intervention 1: } 2 \text { separate goniotomies } \\
\text { Intervention 2: } 1 \text { goniotomy }\end{array}$} \\
\hline Outcomes & \multicolumn{2}{|c|}{$\begin{array}{l}\text { Outcomes: } \\
\begin{array}{ll}1 & \text { IOP: measurements done with an EUA, measured by Schiotz tonometer } \\
2 & \text { Surgical success at } 12 \text { months: an IOP of } 21 \mathrm{~mm} \text { has been considered a criteria for success or failure of IOP } \\
\text { control after surgery. Need for further surgery has also been considered surgical failure }\end{array} \\
3 \text { Corneal diameter with calipers, optic nerve cupping, if visible, and axial length measurement by A-scan } \\
\text { ultrasonography } \\
\text { Intervals at which outcome assessed: } 1 \text { month and } 1 \text { year } \\
\text { Issues with outcome assessment: none } \\
\text { Adverse effects: not reported }\end{array}$} \\
\hline Notes & \multicolumn{2}{|c|}{$\begin{array}{l}\text { Type of study: published } \\
\text { Funding: unrestricted grant from Research to Prevent Blindness and the Sight Conservation Society } \\
\text { Declaration of interest: not reported } \\
\text { Study period: enrollment period: August } 1986 \text { to May } 1987\end{array}$} \\
\hline \multicolumn{3}{|l|}{ Risk of bias } \\
\hline Bias & Authors' judgement & Support for judgement \\
\hline $\begin{array}{l}\text { Random sequence } \\
\text { generation } \\
\text { (selection bias) }\end{array}$ & High risk & $\begin{array}{l}\text { "At the Wills Eye Hospital the eye with the more severe glaucoma was always selected to } \\
\text { undergo two goniotomies. At the Children's Hospital of Denver the selection as to which eye } \\
\text { would undergo two goniotomies was made randomly by means of a coin toss." } \\
\text { Numbers of participants treated in each hospital were not specified }\end{array}$ \\
\hline $\begin{array}{l}\text { Allocation } \\
\text { concealment } \\
\text { (selection bias) }\end{array}$ & High risk & $\begin{array}{l}\text { For the Wills Eye Hospital, allocation was not concealed. For Children's Hospital of Denver, } \\
\text { because coin toss was used for random sequence generation in the paired-eye design, the risk } \\
\text { for allocation concealment is low }\end{array}$ \\
\hline $\begin{array}{l}\text { Masking of } \\
\text { participants and } \\
\text { personnel } \\
\text { (performance bias) }\end{array}$ & Unclear risk & $\begin{array}{l}\text { The surgeon could not be masked. Not masking young children/infants is unlikely to introduce } \\
\text { bias }\end{array}$ \\
\hline $\begin{array}{l}\text { Masking of } \\
\text { outcome } \\
\text { assessment } \\
\text { (detection bias) }\end{array}$ & Unclear risk & We did not know whether outcome assessors were masked. \\
\hline $\begin{array}{l}\text { Incomplete } \\
\text { outcome data } \\
\text { (attrition bias) All } \\
\text { outcomes }\end{array}$ & Low risk & All patients were followed for 1 year. \\
\hline $\begin{array}{l}\text { Selective reporting } \\
\text { (reporting bias) }\end{array}$ & High risk & $\begin{array}{l}\text { Protocol was not available. The Methods section of the paper specified measurement of } \\
\text { corneal diameter, optic nerve cupping, and axial length, but the article did not report these data } \\
\text { in the Results section }\end{array}$ \\
\hline Other bias & Unclear risk & $\begin{array}{l}\text { ee study included both eyes of the same participant, but did not consider intraperson } \\
\text { rrelation of outcomes }\end{array}$ \\
\hline
\end{tabular}




\section{Noureddin 2006}

\begin{tabular}{|c|c|c|}
\hline Methods & \multicolumn{2}{|c|}{$\begin{array}{l}\text { Study design: RCT, paired-eye design } \\
\text { Number randomized: } 8 \text { children with } 16 \text { eyes } \\
\text { After diagnosis, the more severely affected eye was randomly assigned for either trabeculotomy ab externo or } \\
\text { viscocanalostomy. The second eye underwent the alternative surgery } 2 \text { weeks later } \\
\text { Number analyzed: not reported } \\
\text { Losses to follow-up: all children completed } 6 \text { months follow-up; } 5 \text { of } 8 \text { participants completed the } 1 \text { year follow-up } \\
\text { Length of follow-up: } \\
\text { Planned: not reported } \\
\text { Actual: } 12.5 \pm 1.86 \text { months }\end{array}$} \\
\hline Participants & \multicolumn{2}{|c|}{$\begin{array}{l}\text { Country: Lebanon } \\
\text { Age: } 14.68 \pm 17.61 \text { weeks (at time of first operation) } \\
\text { Gender: } 4 / 8(50 \%) \text { boys and } 4 / 8(50 \%) \text { girls } \\
\text { Inclusion criteria: "Eight consecutive patients with newly diagnosed bilateral primary congenital glaucoma were } \\
\text { enrolled in the study...Criteria for diagnosis were the classic symptoms of buphthalmos, photophobia and tearing, in } \\
\text { addition to the signs of a large corneal diameter and IOP }>21 \mathrm{~mm} \text { Hg." } \\
\text { Equivalence of baseline characteristics: different symptoms at diagnosis (eyes had symptoms such as corneal } \\
\text { clouding, buphthalmos, tearing, or a mix of the } 2 \text { or } 3 \text { ) }\end{array}$} \\
\hline Interventions & \multicolumn{2}{|c|}{$\begin{array}{l}\text { Intervention 1: trabeculotomy ab externo } \\
\text { Intervention 2: viscocanalostomy }\end{array}$} \\
\hline Outcomes & \multicolumn{2}{|c|}{ 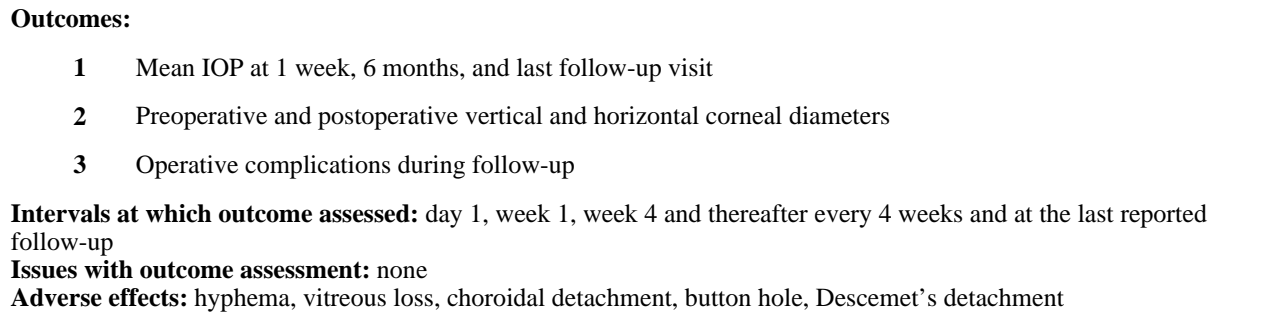 } \\
\hline Notes & \multicolumn{2}{|c|}{$\begin{array}{l}\text { Type of study: published } \\
\text { Funding: not reported } \\
\text { Declaration of interest: the study investigators declared no competing interest } \\
\text { Study period: June } 2003 \text { to December } 2004\end{array}$} \\
\hline \multicolumn{3}{|l|}{ Risk of bias } \\
\hline Bias & Authors' judgement & Support for judgement \\
\hline $\begin{array}{l}\text { Random sequence } \\
\text { generation } \\
\text { (selection bias) }\end{array}$ & Low risk & $\begin{array}{l}\text { "The more severely affected eye was randomly assigned for either trabeculotomy ab externo or } \\
\text { viscocanalostomy. The second eye underwent the alternative surgery } 2 \text { weeks after the first } \\
\text { procedure." }\end{array}$ \\
\hline $\begin{array}{l}\text { Allocation } \\
\text { concealment } \\
\text { (selection bias) }\end{array}$ & Low risk & $\begin{array}{l}\text { The } 2 \text { eyes were concurrently allocated to } 2 \text { interventions, so it is unlikely this design would } \\
\text { introduce selection bias }\end{array}$ \\
\hline $\begin{array}{l}\text { Masking of } \\
\text { participants and } \\
\text { personnel } \\
\text { (performance bias) }\end{array}$ & Unclear risk & $\begin{array}{l}\text { The surgeon could not be masked. Not masking young children/infants is unlikely to introduce } \\
\text { bias }\end{array}$ \\
\hline $\begin{array}{l}\text { Masking of } \\
\text { outcome } \\
\text { assessment } \\
\text { (detection bias) }\end{array}$ & Unclear risk & We did not know whether outcome assessors were masked. \\
\hline $\begin{array}{l}\text { Incomplete } \\
\text { outcome data } \\
\text { (attrition bias) All } \\
\text { outcomes }\end{array}$ & Low risk & $\begin{array}{l}\text { All children completed at least } 10 \text { months follow-up, although } 5 / 8 \text { children completed } 1 \text { year } \\
\text { follow-up, the primary outcome (IOP) reported was at } 6 \text { months }\end{array}$ \\
\hline $\begin{array}{l}\text { Selective reporting } \\
\text { (reporting bias) }\end{array}$ & Unclear risk & $\begin{array}{l}\text { The protocol was not available. Outcomes prespecified in the Methods section matched the } \\
\text { outcomes reported in the Results section }\end{array}$ \\
\hline Other bias & Unclear risk & $\begin{array}{l}\text { The study included both eyes of the same participant, but did not consider intraperson } \\
\text { correlation of outcomes }\end{array}$ \\
\hline \multicolumn{3}{|l|}{ Senft 1989} \\
\hline Methods & \multicolumn{2}{|c|}{ Study design: RCT, paired-eye design } \\
\hline
\end{tabular}

Cochrane Database Syst Rev. Author manuscript; available in PMC 2016 January 30. 


\begin{tabular}{|c|c|c|}
\hline & \multicolumn{2}{|c|}{$\begin{array}{l}\text { Number randomized (total and per group): } 10 \text { children with } 20 \text { eyes } \\
\text { Number analyzed (total and per group): not reported } \\
\text { Losses to follow-up: not reported } \\
\text { Length of follow-up: } \\
\text { Planned: not reported } \\
\text { Actual: } 9.5 \pm 4.8 \text { months (range } 2 \text { to } 15 \text { months) }\end{array}$} \\
\hline Participants & \multicolumn{2}{|c|}{$\begin{array}{l}\text { Country: Saudi Arabia } \\
\text { Age: } 5.7 \pm 3.9 \text { months (range } 4 \text { days to } 12 \text { months) } \\
\text { Gender: } 6 / 10(60 \%) \text { boys and } 4 / 10(40 \%) \text { girls } \\
\text { Inclusion criteria: "Patients included in this study were children with congenital glaucoma who were younger than age } \\
5 \text { years. Diagnosis of congenital glaucoma was established on the basis of intraocular pressure (IOP) elevation above } 23 \\
\text { mm Hg by applanation, enlargement in the horizontal corneal diameter beyond } 12 \mathrm{~mm} \text {, and typical optic nerve changes } \\
\text { suggestive of glaucomatous cupping." } \\
\text { Equivalence of baseline characteristics: each surgery was done on the same patients: IOP in the surgical goniotomy } \\
\text { group: } 28.4 \pm 4.6 \mathrm{~mm} \mathrm{Hg} \text {; IOP in the neodymium-YAG laser goniotomy group: } 29.5 \pm 11.0 \mathrm{~mm} \mathrm{Hg}\end{array}$} \\
\hline Interventions & \multicolumn{2}{|c|}{$\begin{array}{l}\text { Intervention 1: surgical goniotomy under general anesthesia } \\
\text { Intervention 2: neodymium-YAG laser goniotomy under oral chloral hydrate sedation }\end{array}$} \\
\hline Outcomes & \multicolumn{2}{|c|}{$\begin{array}{l}\text { Outcomes: } \\
1 \text { Mean IOP following surgery or laser treatment } \\
2 \text { Corneal diameters } \\
3 \text { C/D ratio } \\
\text { Intervals at which outcome assessed: not reported } \\
\text { Issues with outcome assessment: none } \\
\text { Adverse effects: "Localized, self-limited intraocular hemorrhage was noted for both surgical and laser procedures. No } \\
\text { patient in the surgical group had a significant hyphema during the procedure or postoperatively. Bleeding in the laser } \\
\text { treated eyes was observed occasionally and was always insignificant." }\end{array}$} \\
\hline Notes & \multicolumn{2}{|c|}{$\begin{array}{l}\text { Type of study: published } \\
\text { Funding: Research Department, King Khaled Eye Specialist Hospital } \\
\text { Declaration of interest: "The authors have no proprietary interest in the Lasag Co." } \\
\text { Study period: not reported }\end{array}$} \\
\hline \multicolumn{3}{|l|}{ Risk of bias } \\
\hline Bias & Authors' judgement & Support for judgement \\
\hline $\begin{array}{l}\text { Random sequence } \\
\text { generation } \\
\text { (selection bias) }\end{array}$ & Unclear risk & $\begin{array}{l}\text { "One eye of each patient was chosen for surgical or Nd-YAG laser treatment in a randomized, } \\
\text { double-masked fashion." The method for random sequence generation was not specified }\end{array}$ \\
\hline $\begin{array}{l}\text { Allocation } \\
\text { concealment } \\
\text { (selection bias) }\end{array}$ & Low risk & The 2 eyes were allocated concurrently to 2 interventions. \\
\hline $\begin{array}{l}\text { Masking of } \\
\text { participants and } \\
\text { personnel } \\
\text { (performance bias) }\end{array}$ & Unclear risk & $\begin{array}{l}\text { The study stated that "One eye of each patient was chosen for surgical or Nd-YAG laser } \\
\text { treatment in a randomized, double-masked fashion", but did not specify who was masked }\end{array}$ \\
\hline $\begin{array}{l}\text { Masking of } \\
\text { outcome } \\
\text { assessment } \\
\text { (detection bias) }\end{array}$ & Low risk & "All IOP readings were obtained...in a double-masked fashion." \\
\hline $\begin{array}{l}\text { Incomplete } \\
\text { outcome data } \\
\text { (attrition bias) All } \\
\text { outcomes }\end{array}$ & Unclear risk & $\begin{array}{l}\text { Participants were followed at different time points. We are unclear how many participants } \\
\text { were included in the final follow-up }\end{array}$ \\
\hline $\begin{array}{l}\text { Selective reporting } \\
\text { (reporting bias) }\end{array}$ & Unclear risk & $\begin{array}{l}\text { The protocol was not available. Outcomes prespecified in the Methods section matched the } \\
\text { outcomes reported in the Results section }\end{array}$ \\
\hline Other bias & Unclear risk & $\begin{array}{l}\text { The study included both eyes of the same participant, but did not consider intraperson } \\
\text { correlation of outcomes }\end{array}$ \\
\hline
\end{tabular}

* means reported as mean \pm standard deviation

CCT: controlled (quasi-randomized) clinical trial

C/D ratio: cup/disc ratio

EUA: examination under anesthesia

IOP: intraocular pressure 
$\mathrm{mm} \mathrm{Hg}$ : millimeter mercury

RCT: randomized controlled trial

YAG: yttrium aluminum garnet 
Characteristics of excluded studies [ordered by study ID]

\begin{tabular}{|l|l|}
\hline Study & Reason for exclusion \\
\hline Agarwal 1997 & $\begin{array}{l}\text { The study included children with ages ranging from 9 days to 7 years with various diagnoses (aniridia, mesodermal } \\
\text { dysgenesis); did not report outcome data for PCG for children under 5 years old separately }\end{array}$ \\
\hline Asseman 1972 & Retrospective cohort study \\
\hline Bohnke 1990 & Not PCG \\
\hline Colev 1977 & $\begin{array}{l}\text { Only } 8 \text { children, 1 was secondary glaucoma, age ranged from } 3 \text { months to } 6 \text { years; did not separate results by age or by } \\
\text { diagnosis }\end{array}$ \\
\hline Dascotte 1989 & Did not give any participant characteristics, whether primary or secondary glaucomas or age at which surgery occurred \\
\hline Demailly 1992 & Did not separate results by diagnosis - primary versus secondary infantile glaucoma \\
\hline Ding 2011 & Included participants with infantile glaucoma and juvenile glaucoma but did not report separate results for PCG \\
\hline Gimbel 1995 & Included adult patients; not PCG \\
\hline Kubota 2001 & Participants' ages ranged from 11 to 50 years; not PCG \\
\hline Ozcan 2004 & Retrospective cohort study \\
\hline Plager 1999 & Interventional case series (no comparison group) \\
\hline Rodrigues 2006 & Conference abstract only; eligibility criteria unclear; study investigators did not respond to emailed query \\
\hline Tamcelik 2008 & Did not separate outcomes by participant age; only outcome measure reported was tube exposure \\
\hline Tamcelik 2010a & Did not separate results by diagnosis - primary versus secondary infantile glaucoma \\
\hline Tamcelik 2010b & Did not separate outcomes by participants' age, only outcome measure reported was tube exposure \\
\hline
\end{tabular}

PCG: primary congenital glaucoma 
Characteristics of ongoing studies [ordered by study ID]

\begin{tabular}{|c|c|}
\hline \multicolumn{2}{|l|}{ NCT01460017 } \\
\hline Trial name or title & Comparison Between Deep Sclerectomy and Traditional Trabeculotomy \& Trabeculectomy in Congenital Glaucoma \\
\hline Methods & $\begin{array}{l}\text { Study design: randomized controlled trial } \\
\text { Number randomized (total and per group): } 40 \text { participants; per group not reported } \\
\text { Number analyzed (total and per group): not reported } \\
\text { Losses to follow-up: not reported } \\
\text { Length of follow-up: } \\
\text { Planned: } 6 \text { months } \\
\text { Actual: unknown }\end{array}$ \\
\hline Participants & $\begin{array}{l}\text { Country: Saudi Arabia } \\
\text { Age: } 0 \text { to } 12 \text { years } \\
\text { Gender: both genders were eligible } \\
\text { Inclusion criteria: congenital glaucoma with enlarged corneal diameter more than } 11 \mathrm{~mm} \text { and intraocular pressure } \\
\text { above } 21 \mathrm{~mm} \mathrm{Hg} \text {, including corneal edema or Habb's Stria with or without optic disc cupping; or primary or secondary } \\
\text { congenital glaucoma to ocular or systemic abnormalities; age } 0 \text { to } 12 \text { years } \\
\text { Exclusion criteria: previous intervention; secondary glaucoma caused by surgical intervention, ocular co-morbidity, } \\
\text { medications or trauma }\end{array}$ \\
\hline Interventions & $\begin{array}{l}\text { Intervention 1: deep sclerectomy surgery } \\
\text { Intervention 2: combined trabeculectomy and trabeculotomy surgery }\end{array}$ \\
\hline Outcomes & $\begin{array}{l}\text { Primary outcome: reduction in intraocular pressure at } 6 \text { months } \\
\text { Secondary outcome: not specified }\end{array}$ \\
\hline Starting date & November 2011 \\
\hline Contact information & Saleh A. Al-Obeidan, MD; +96614786100 ext 1425; alobeidan@yahoo.com \\
\hline Notes & $\begin{array}{l}\text { Clinicaltrials.gov: NCT01460017 } \\
\text { "The recruitment status of this study is unknown because the information has not been verified recently" }\end{array}$ \\
\hline \multicolumn{2}{|l|}{ NCT01494974 } \\
\hline Trial name or title & Comparison of the Ahmed Glaucoma Valve FP7 and FP8 in Pediatric Glaucoma \\
\hline Methods & $\begin{array}{l}\text { Study design: randomized controlled trial } \\
\text { Number randomized (total and per group): total: } 40 \text { participants; each group not reported } \\
\text { Length of follow-up: } \\
\text { Planned: } 1 \text { year } \\
\text { Actual: unknown }\end{array}$ \\
\hline Participants & 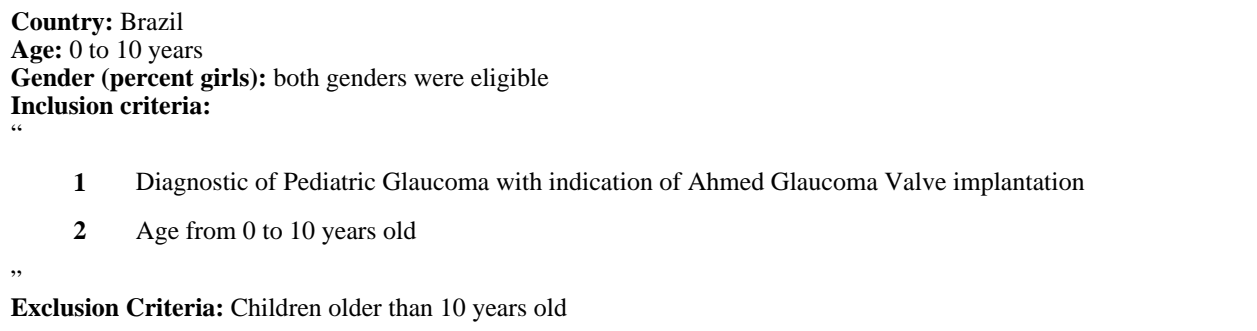 \\
\hline Interventions & $\begin{array}{l}\text { Intervention 1: FP7 implant } \\
\text { Intervention 2: FP8 implant }\end{array}$ \\
\hline Outcomes & $\begin{array}{l}\text { Primary outcome: position of the drainage implant plate at } 1 \text { year after surgery } \\
\text { Secondary outcome: variation in IOP preoperative and postoperative at } 1 \text { year }\end{array}$ \\
\hline Starting date & December 2011 \\
\hline Contact information & Camila F Netto, MD; 1199177717; milanetto@gmail.com \\
\hline Notes & $\begin{array}{l}\text { Clinicaltrials.gov: NCT01494974 } \\
\text { "This study is currently recruiting participants" }\end{array}$ \\
\hline \multicolumn{2}{|l|}{ NCT02121171 } \\
\hline Trial name or title & $\begin{array}{l}\text { Combined Trab+Trab Versus Combined Trab+Trab With Subconjunctival Implantation of Ologen for Primary } \\
\text { Congenital Glaucoma }\end{array}$ \\
\hline
\end{tabular}




\begin{tabular}{|c|c|}
\hline Methods & $\begin{array}{l}\text { Study design: randomized controlled trial } \\
\text { Number randomized (total and per group): total: } 40 \text { participants; each group not reported } \\
\text { Length of follow-up: } \\
\text { Planned: } 24 \text { months } \\
\text { Actual: unknown }\end{array}$ \\
\hline Participants & $\begin{array}{l}\text { Country: Azerbaijan } \\
\text { Age: } 0 \text { to } 12 \text { years } \\
\text { Gender (percent girls): both genders were eligible } \\
\text { Inclusion criteria: } \\
\text { " } \\
\quad \mathbf{1} \text { Any case diagnosed as congenital glaucoma with enlarged corneal diameter more than } 11 \mathrm{~mm} \text { and } \\
\text { intraocular pressure above } 21 \mathrm{mmHg} \text {, including corneal edema or Haab's stria with or without optic disc } \\
\text { cupping } \\
\mathbf{2} \text { Any case diagnosed as primary or secondary congenital glaucoma to ocular or systemic abnormalities } \\
\quad 3 \text { Within the age of }(0-12) \text {. } \\
\text { Exclusion criteria: } \\
\text { "Cases of congenital glaucoma with previous intervention. Age above } 12 \text { Yrs. Cases with secondary glaucoma caused } \\
\text { by surgical intervention, ocular co-morbidity, medications or trauma" }\end{array}$ \\
\hline Interventions & $\begin{array}{l}\text { Intervention 1: combined trabeculotomy-trabeculectomy with subconjunctival Ologen matrix implant implantation } \\
\text { Intervention 2: combined trabeculotomy and trabeculectomy }\end{array}$ \\
\hline Outcomes & $\begin{array}{l}\text { Primary outcome intraocular pressure (IOP) reduction at postoperative up to } 24 \text { months } \\
\text { Secondary outcome postoperative complications and appearances at postoperative up to } 24 \text { months }\end{array}$ \\
\hline Starting date & 19 April 2014 \\
\hline Contact information & Nigar Makhmudova: Ophthalmologist at National Centre of Ophthalmology; email not reported \\
\hline Notes & $\begin{array}{l}\text { Clinicaltrials.gov: NCT02121171 } \\
\text { "This study is ongoing, but not recruiting participants" }\end{array}$ \\
\hline \multicolumn{2}{|l|}{ Shreyas 2014} \\
\hline Trial name or title & Comparison of 2 surgical treatments in glaucoma presenting from birth \\
\hline Methods & $\begin{array}{l}\text { Study design: randomized controlled trial } \\
\text { Number randomized (total and per group): not reported } \\
\text { Length of follow-up: } \\
\text { Planned: } 1 \text { year } \\
\text { Actual: unknown }\end{array}$ \\
\hline Participants & $\begin{array}{l}\text { Country: India } \\
\text { Age: } 0 \text { to } 2 \text { years } \\
\text { Gender (percent girls): both genders were eligible } \\
\text { Inclusion criteria: } \\
\text { “ } \\
\begin{array}{ll}\mathbf{1} & \text { Patients of primary congenital glaucoma } \\
\mathbf{2} & \text { Age }<2 \text { years } \\
\mathbf{3} & \text { Written informed consent } \\
\text { Exclusion } & \text { Criteria: } \\
\text { “ } & \\
\mathbf{1} & \text { Secondary glaucoma } \\
\mathbf{2} & \text { Associated ocular/systemic anomalies } \\
\mathbf{3} & \text { Previous intraocular surgeries } \\
\mathbf{4} & \text { One eyed patient } \\
, & \end{array}\end{array}$ \\
\hline Interventions & $\begin{array}{l}\text { Intervention 1: combined trabeculotomy-trabeculectomy } \\
\text { Intervention 2: illuminated microcatheter: } 360 \text { degree assisted trabeculotomy }\end{array}$ \\
\hline Outcomes & $\begin{array}{l}\text { Primary outcome intraocular pressure at } 1,4,6 \text { and } 12 \text { months } \\
\text { Secondary outcomes: }\end{array}$ \\
\hline
\end{tabular}




\begin{tabular}{l|rl} 
& $\mathbf{1}$ & Achieving completion of trabeculotomy using illuminated microcatheter at $1,4,6$ and 12 months \\
& $\mathbf{2}$ & Need for anti glaucoma medication to achieve target IOP at $1,4,6$ and 12 months \\
& $\mathbf{3}$ & Optic disc status at 1, 4, 6 and 12 months \\
& $\mathbf{4}$ & Surgical complications at 1, 4, 6 and 12 months \\
\hline Starting date & 16 May 2014 \\
\hline Contact information & Shreyas TS: tanujdada@ hotmail.com \\
\hline Notes & WHO International Clinical Trials Registry Platform (ICTRP): Trial ID: CTRI/2014/05/004603 \\
& The study is "closed to recruitment of participants". \\
\hline
\end{tabular}

IOP: intraocular pressure

$\mathrm{mm}$ : millimeter

$\mathrm{mm} \mathrm{Hg}$ : millimeter of mercury

WHO: World Health Organization 